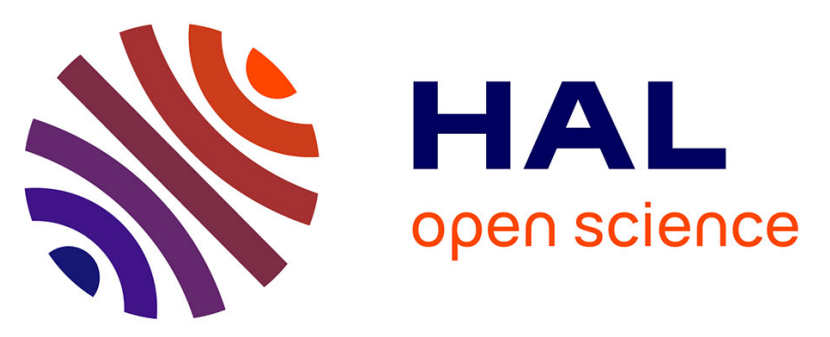

\title{
Impact of Coinage Metal Insertion on the Thermoelectric Properties of GeTe Solid-State Solutions
}

Bhuvanesh Srinivasan, Romain Gautier, Francesco Gucci, Bruno Fontaine, Jean-François Halet, François Cheviré, Catherine Boussard-Plédel, Michael J. Reece, Bruno Bureau

\section{To cite this version:}

Bhuvanesh Srinivasan, Romain Gautier, Francesco Gucci, Bruno Fontaine, Jean-François Halet, et al.. Impact of Coinage Metal Insertion on the Thermoelectric Properties of GeTe Solid-State Solutions. Journal of Physical Chemistry C, 2018, 122 (1), pp.227-235. 10.1021/acs.jpcc.7b10839 . hal-01709523v2

\section{HAL Id: hal-01709523}

https://hal-univ-rennes1.archives-ouvertes.fr/hal-01709523v2

Submitted on 29 Mar 2018

HAL is a multi-disciplinary open access archive for the deposit and dissemination of scientific research documents, whether they are published or not. The documents may come from teaching and research institutions in France or abroad, or from public or private research centers.
L'archive ouverte pluridisciplinaire HAL, est destinée au dépôt et à la diffusion de documents scientifiques de niveau recherche, publiés ou non, émanant des établissements d'enseignement et de recherche français ou étrangers, des laboratoires publics ou privés. 


\title{
Impact of Coinage Metal Insertion on the Thermoelectric Properties of GeTe
}

\section{Solid-State Solutions}

\author{
Bhuvanesh Srinivasan ${ }^{a *}$, Régis Gautier ${ }^{a *}$, Francesco Gucci ${ }^{b}$, Bruno Fontaine ${ }^{a}$, Jean-François Halet ${ }^{a}$, \\ François Cheviré ${ }^{a}$, Catherine Boussard-Pledel ${ }^{a}$, Michael J. Reece ${ }^{b}$ and Bruno Bureau ${ }^{a}$ \\ ${ }^{a}$ Institut des Sciences Chimiques de Rennes, UMR 6226, CNRS- Ecole Nationale Supérieure de Chimie de Rennes- \\ Université de Rennes 1, 35042 Rennes, France. \\ ${ }^{b}$ School of Engineering and Materials Science, Queen Mary University of London, London E1 4NS, United Kingdom. \\ * Correspondence - bhuvanesh.srinivasan@univ-rennes1.fr; Tel.: +33-223233688 \\ regis.gautier@ensc-rennes.fr; Tel.: +33-223238122 \\ † Electronic Supplementary Information (ESI) available
}

\begin{abstract}
A comprehensive study on the thermoelectric effect of Ag substitution in GeTe solid solutions, a congenital base for high efficient TAGS-m $\left[(\mathrm{GeTe})_{\mathrm{m}}(\mathrm{AgSbTe})_{100-\mathrm{m}}\right]$ thermoelectric materials, was performed. First-principles calculations were carried out to probe the changes arising from doping on the electronic band structure of GeTe, which exhibits a rhombohedral $(r)$ structure at temperatures lower than $700 \mathrm{~K}$. Aliovalent Ag substitution in GeTe increases the hole concentration and decreases the thermoelectric figure of merit $(\mathrm{zT})$ due to the reduction of the Seebeck coefficient, which is ascribed mainly to the lowering of the Fermi level together with the loss of band degeneracy. Band structure and effective mass calculations of these doped materials also point to a soaring contribution from several hole pockets in the valence band. First-principles calculations carried out with two other group-11 transition metals $(\mathrm{Cu}, \mathrm{Au})$ reveal that silver substitution has the lowest impact on the thermopower of $\mathrm{r}$ -
\end{abstract}


GeTe. A mean zT of $\sim 0.85$ at $773 \mathrm{~K}$ is achieved for $\mathrm{Ge}_{1-x} \mathrm{Ag}_{\mathrm{x}} \mathrm{Te}(x \leq 0.04)$ solid solutions. The study highlights the limits in doping just a coinage metal to GeTe and recapitulates the need for pair substitution to enhance the thermoelectric properties of GeTe-based solid-state solutions.

\section{Introduction}

The global need for energy management, particularly the conversion of waste heat to useful electricity is becoming increasingly important owing to recent environmental and energy concerns ${ }^{1-3}$. Among the several approaches for solid-state compound conversion between heat and electricity including fuel cells $^{4}$, photovoltaics ${ }^{5}$, batteries ${ }^{6}$ and supercapacitors ${ }^{6}$, thermoelectric (TE) devices have significant potential in tackling the challenges of energy sustainability offering excellent features: extensive lifetime, highly reliable and scalable, environmentally friendly, quiet, lower maintenance costs, etc. ${ }^{7-9}$. The thermoelectric material's potential to convert waste heat into electricity is quantified by the dimensionless figure of merit zT as given by equation (1),

$$
z T=\frac{S^{2} \sigma T}{\kappa_{\text {total }}}
$$

where $S, \sigma, T$ and $\kappa_{\text {total }}$ are the Seebeck coefficient, electrical conductivity, temperature, and total thermal conductivity, respectively.

The fact that these thermoelectric transport properties are highly interrelated, throws a greater challenge in enhancing zT. Advances in recent times show that it is feasible to enhance zT by a number of approaches: Quantum confinement of electron charge carriers ${ }^{10}$; synergistic nano-structuring ${ }^{11-14}$; nano-inclusions which enable acoustic phonon scatterings ${ }^{15,16}$; electron filtering ${ }^{17}$; convergence of electronic band valleys ${ }^{18-20}$; fostering resonant levels by impurities inside the valence band ${ }^{21}$; alloying 
to create point defects ${ }^{22,23}$; and complex crystal structures like skutterudites ${ }^{24,25}$, Zintl compounds ${ }^{26,27}$, hetero-structured superlattice thin-films ${ }^{28}$ and even semi-conducting glasses ${ }^{29-32}$.

Amongst the state-of-the-art thermoelectric materials, the extensively studied PbTe based materials are limited by their toxicity for any practical applications, despite their high zT. Recently, GeTe based materials have emerged as a clear alternative choice. $\mathrm{Ge}_{0.87} \mathrm{~Pb}_{0.13} \mathrm{Te}$ with/without doping of 3 mol\% $\mathrm{Bi}_{2} \mathrm{Te}_{3}$ have reportedly shown an impressive $z \mathrm{~T} \sim 2$ in the temperature range $700-773 \mathrm{~K}$ due to thermodynamically driven phase segregations and band convergence caused by the donor dopant capability of $\mathrm{Bi}$ and $\mathrm{Pb}{ }^{33-36}$. However, the concentration of $\mathrm{Pb}$ is still quite high (hazardous) in these materials. High zT values around $750 \mathrm{~K}$ have been attained by simple solid-state substitution of Ge in GeTe by 10 mol\% Sb $(z \mathrm{~T} \sim 1.8)^{37}, 6$ mol\% Bi $(z \mathrm{~T} \sim 1.3)^{38}, 5$ mol\% Mn $(z \mathrm{~T} \sim 1.3)^{39}, 2.5 \mathrm{~mol} \% \mathrm{Sn}+2.5$ mol\% $\mathrm{Pb}(z \mathrm{~T} \sim 1.2)^{40}$ and $2 \mathrm{~mol} \% \ln (z \mathrm{~T} \sim 1.3)^{41}$.

Other well established classes of high performance materials involving carrier and phonon engineering of GeTe are the so-called TAGS alloys with composition $(\mathrm{GeTe})_{x}(\mathrm{AgSbTe})_{1-x}$ exhibiting zT values of more than $1^{42-45}$. Similar values of zT at mid-temperature ranges $(600-800 \mathrm{~K})$ were achieved for different isovalent substitution of TAGS, e.g., substitution of $\mathrm{Ag}^{+}$by $\mathrm{Li}^{+46}, \mathrm{Sb}^{3+}$ by $\mathrm{In}^{3+} 47, \mathrm{Ge}^{2+}$ by $\mathrm{Sn}^{2+} 48$ and aliovalent substitution of $\mathrm{Ge}^{2+}$ by $\mathrm{Dy}^{+3} 49 . \mathrm{Sb}$ and $\mathrm{Ag}$ are the principle dopants in TAGS. Several studies have clearly explained the structure and thermoelectric properties of the Ge-Sb-Te system, to emphasize the role of $\mathrm{Sb}$ in $\mathrm{GeTe} \mathrm{e}^{37,50,51}$, but not much information is available for the Ge-Ag-Te system. Very recently, Levin ${ }^{52}$ reported some interesting findings by correlating variations of the Seebeck coefficient with ${ }^{125} \mathrm{Te}-\mathrm{NMR}$ results on GeTe based materials, where a small concentration of Ge was substituted by $\mathrm{Ag}$ and/or Sb. However, there have been no reports on the complete thermoelectric properties ( $z T$ calculations) of $\mathrm{Ge}_{1-x} \mathrm{Ag}_{\mathrm{x}} \mathrm{Te}(0 \leq x \leq 0.1)$ compounds. 
The crystal structure of GeTe-based compounds undergoes a second-order phase transition from rhombohedral symmetry (low temperature phase) to cubic symmetry (high temperature phase) at around $700 \mathrm{~K}^{36,44}$. Some previous theoretical calculations of density-functional theory (DFT) type carried out on pristine GeTe suggest the presence of a large number of Ge vacancies leading to high concentration of holes in the valence band ${ }^{53}$, and the displacement of Ge and Te atoms as the main reason for the structural transition ${ }^{54}$. Hoang et al. ${ }^{55}$ performed first-principles calculations by assuming a rock-salt $\mathrm{NaCl}$-structure for GeTe to provide some insights on the role of dopants in TAGS alloys. But the band structure calculations on the rhombohedral phase (below $700 \mathrm{~K}$ ) of GeTe have not been exploited until recently ${ }^{56}$. The goal of this article is to exclusively elucidate the effects of partially replacing $\mathrm{Ge}$ by coinage metals $(\mathrm{M}=\mathrm{Cu}, \mathrm{Ag}$ and $\mathrm{Au})$ on the band structure and transport properties of the rhombohedral $\mathrm{Ge}_{1-\mathrm{x}} \mathrm{M}_{\mathrm{x}} \mathrm{Te}$ system. Indeed, we report herein the decline in the thermoelectric performance of $p$-type $\mathrm{Ge}_{1-\mathrm{x}} \mathrm{Ag} \mathrm{x}$ Te high quality crystalline ingots with the increase in $\mathrm{Ag}$ concentration. The solid-state solutions also exhibit a low lattice thermal conductivity of $\sim 1 \mathrm{~W} / \mathrm{mK}$ at $773 \mathrm{~K}$, on par with other high performance TE materials. The decrease in zT with Ag content is primarily attributed to the reduction of the Seebeck coefficient, which arises due to the following reasons: (i) the substitution of $\mathrm{Ag}^{+}$at $\mathrm{Ge}^{2+}$ site in GeTe enhances the $p$-type carrier concentration due to the aliovalent nature of $\mathrm{Ag}^{+}$ with respect of $\mathrm{Ge}^{2+}$; (ii) the loss of band degeneracy; and (iii) the lowering of the Fermi level $\left(\mathrm{E}_{\mathrm{F}}\right)$. The distinct increase in the electronic part of the thermal conductivity upon Ag doping plays also a role in the reduction of zT. The transport properties of GeTe compounds computed within a semi-classical approach show that among the coinage metals ( $\mathrm{Cu}, \mathrm{Ag}$ and $\mathrm{Au})$, silver outperforms the others. 


\section{Materials and Methods}

\section{Reagents}

Ge (Umicore, 5N), Te (JGI, 5N) and Ag (Alfa Aesar, 99.999\%) were used for synthesis without involving any further purification process.

\section{Synthesis}

Samples of $\mathrm{Ge}_{1-x} \mathrm{Ag}_{\mathrm{x}} \mathrm{Te}(x=0.00-0.06)$ solid-state solutions were synthesized using the vacuum-sealed tube melting processing. Appropriate stoichiometric amounts of the starting elements of $\mathrm{Ge}, \mathrm{Ag}$ and $\mathrm{Te}$ were introduced into a fused silica tube that had previously been cleaned with hydrofluoric (HF) acid and distilled water and dried under vacuum. The ampoules were sealed under a vacuum of $10^{-6}$ Torr, then placed in a rocking furnace and slowly heated up to $1000{ }^{\circ} \mathrm{C}$ over a period of 12 hours, then held at that temperature for 15 hours and slowly cooled down to room temperature over 12 hours. The obtained ingots were cut and polished to required shapes and dimensions for various thermoelectric measurements.

\section{Powder X-ray diffraction}

$\mathrm{X}$-ray diffraction (XRD) patterns were recorded at room temperature in the $2 \theta$ range $15-120^{\circ}$ with a step size of $0.026^{\circ}$ and a scan time per step of $400 \mathrm{~s}$ using a PANalytical X'Pert Pro diffractometer (Cu $K-L_{2,3}$ radiation, $\lambda=1.5418 \AA$, PIXcel 1D detector). $\mathrm{Ge}_{1-\mathrm{x}} \mathrm{Ag}_{\mathrm{x}} \mathrm{Te}$ lattice parameters were estimated from Lebailtype profile fits carried out with the Fullprof program using on the hexagonal cell of the $R 3 m$ space group and the Pseudo-Voigt profile function ${ }^{57}$.

\section{Hall measurements}

The Hall measurements were carried out at room temperature using a home-made four-point probe setup (Van der Pauw method), where a fixed magnetic field of $0.112 \mathrm{~T}$ and dc current of $15 \mathrm{~mA}$ was 
applied. The measurements were made on square-shaped samples of dimensions $\sim 5 \times 5 \times 2 \mathrm{~mm}^{3}$. The carrier concentration $(n)$ and mobility $(\mu)$ were computed from carrier sheet density $\left(n_{s}\right)$, sheet resistance $\left(R_{s}\right)$ and Hall Voltage $\left(V_{H}\right)$ using the following equations,

$$
\begin{gathered}
n_{S}=n x t=\frac{I B}{e\left|V_{H}\right|} \\
\mu=1 /\left(e n_{S} R_{S}\right)
\end{gathered}
$$

where e, B, I and t are the charge of the electron, magnetic field, current and thickness of the sample, respectively. The values of carrier density obtained were quite consistent with a standard deviation of less than $2 \%$.

\section{Electrical and thermal transport}

The electrical conductivity and Seebeck coefficients were measured simultaneously from room temperature to $773 \mathrm{~K}$ using a commercial instrument (LSR-3, Linseis Inc.), in He atmosphere. The measurements were made on parallelepiped-shaped samples of dimension $\sim 10 \times 2 \times 2 \mathrm{~mm}^{3}$.

The thermal diffusivity $\mathrm{D}$ was measured from room temperature to $773 \mathrm{~K}$ using the laser flash diffusivity method in a Netzsch LFA-457 instrument. Disc shaped samples of $10 \mathrm{~mm}$ diameter and $\sim 2 \mathrm{~mm}$ thickness were used for the measurements. The heat capacity, $C_{p}$, was derived using the Dulong-Petit relation as in equation (4),

$$
C_{p}=3 R / M
$$

where $\mathrm{R}$ is the gas constant and $\mathrm{M}$ is the molar mass. Dulong-Petit relation holds well for such materials $41,47,50,58,59$

The total thermal conductivity $\kappa$ was calculated using equation (4),

$$
\kappa_{\text {total }}=D C_{p} \rho
$$


where $\rho$ is the density of the sample. The density of the discs was measured using Archimedes' principle.

The uncertainty in the results for the values of electrical and thermal transport properties are $\sim 5 \%$ and $\sim 7 \%$, respectively. Error bars are not shown in the figures to facilitate the readability of the curves.

\section{Microscopic analysis}

Scanning electron microscopy (SEM) and Energy Dispersive X-Ray Spectroscopy (EDX) analysis were performed using a JEOL JSM 7100F microscope on polished bulk surface of the samples.

\section{Computational procedures}

DFT geometry optimizations of $\mathrm{M}_{\mathrm{x}} \mathrm{Ge}_{1-\mathrm{x}} \mathrm{Te}(\mathrm{x}=0.00,0.042 ; \mathrm{M}=\mathrm{Cu}, \mathrm{Ag}, \mathrm{Au})$ were carried out with the CASTEP16.1 ${ }^{60}$ code using the GGA PBE functional ${ }^{61}$. Dispersion corrections were added in the calculations within the scheme proposed by Tkatchenko and Scheffler ${ }^{62}$. In order to model the crystal structure of $\mathrm{M}_{0.042} \mathrm{Ge}_{0.958} \mathrm{Te}$, a supercell $(2 \times 2 \times 2)$ was built from the hexagonal cell of GeTe. The $P$ - $3 m 1$ (No. 164) space group was considered for both $\mathrm{M}_{x} \mathrm{Ge}_{1-\mathrm{x}} \mathrm{Te}$ models $(x=0.00,0.042)$. Cell parameters and atomic positions of $\mathrm{M}_{0.042} \mathrm{Ge}_{0.958} \mathrm{Te}$ were both relaxed. All ultra-soft pseudopotentials were generated using the OTF_ultrasoftpseudopotential generator included in the program. The cut-off energy for plane-waves was set at $500 \mathrm{eV}$. The electronic wave function was sampled with $110 k$-points in the first Brillouin zone using the Monkhorst-Pack method ${ }^{63}$. For the electronic band structures, we used the fullpotential linearized augmented plane wave (FLAPW) approach, as implemented in the WIEN2K code ${ }^{64}$. For comparison, the band structure of GeTe was computed using the same unit cell and space group as $\mathrm{M}_{0.042} \mathrm{Ge}_{0.958} \mathrm{Te}$. A plane wave cut-off corresponding to $R_{M T} K_{\max }=7$ was used. The radial wave functions inside the non-overlapping muffin-tin spheres were expanded up to $I_{\max }=12$. The charge density was Fourier expanded up to $G_{\max }=12 \AA^{-1}$. Total energy convergence was achieved with a Brillouin zone (BZ) integration mesh of $500 k$-points. 
The carrier effective mass $\left(\mathrm{m}^{*}\right)$ was derived for each sample using the measured room temperature Seebeck coefficient (S) and the carrier concentration (n), and considering a single parabolic band model 65,66. The chemical potential $(\mu)$ can be estimated using equation (6) with $\lambda=0$ (acoustic-phonon scattering), where $F_{j}(\mu)$ are the Fermi integrals given by equation (7). The hole effective mass can then be determined from equation (8).

$$
\begin{gathered}
S=\frac{K_{B}}{e}\left\{\frac{(2+\lambda) F_{1+\lambda}(\mu)}{(1+\lambda) F_{\lambda}(\mu)}-\mu\right\} \\
F_{j}(\mu)=\int_{0}^{\infty} \frac{\xi^{j} d \xi}{1+e^{(\xi-\mu)}} \\
m^{*}=\frac{h^{2}}{2 k_{B} T}\left[\frac{n}{4 \pi F_{1 / 2}(\mu)}\right]^{2 / 3}
\end{gathered}
$$

The electronic transport coefficients for $\mathrm{M}_{x} \mathrm{Ge}_{1-\mathrm{x}} \mathrm{Te}(\mathrm{M}=\mathrm{Cu}, \mathrm{Ag}, \mathrm{Au} ; x=0.04)$ were calculated within the Boltzmann Transport Equation (BTE) with constant relaxation time for the electrons $\tau$ and a rigid band structure approximation, ${ }^{67,68}$ as implemented in the BoltzTrap-1.2.5 code ${ }^{69} .10,000$ k-points in the BZ were used to compute the band derivatives and the density of states for the transport calculations.

\section{Results and Discussion}

Crystalline ingots of $\mathrm{Ge}_{1-\mathrm{x}} \mathrm{Ag}_{\mathrm{x}} \mathrm{Te}(x=0.00,0.01,0.02,0.04$ and 0.06$)$ were synthesized by vacuum sealedtube melt processing. Figure $1 \mathrm{a}$ shows the room temperature X-ray diffraction pattern of all the samples. Sharp reflections indicate the polycrystalline nature of the synthesized ingots. All the main reflections could be indexed based on a rhombohedral GeTe structure (PDF\#47-1079, R3m space group). Minor reflections of Ge impurities can be detected in some samples. The rhombohedral phase is further confirmed by the presence of double reflections ${ }^{33,37}[(024)$ and $(220)]$ in the range of $2 \theta$ values between $41^{\circ}$ to $44^{\circ}$. As shown in Figure $1 \mathrm{c}$, a progressive evolution of the lattice parameters $a$ (decreasing trend) 
and $c$ (increasing trend) is observed upon increasing Ag content leading to a continuous decrease of the hexagonal cell volume, as illustrated in Figure 1b. The linear evolution in the lattice parameters for $x=$ $0.00-0.04$ follows the solid-solution Vegard's law, as Ag is progressively incorporated into the GeTe crystal structure.
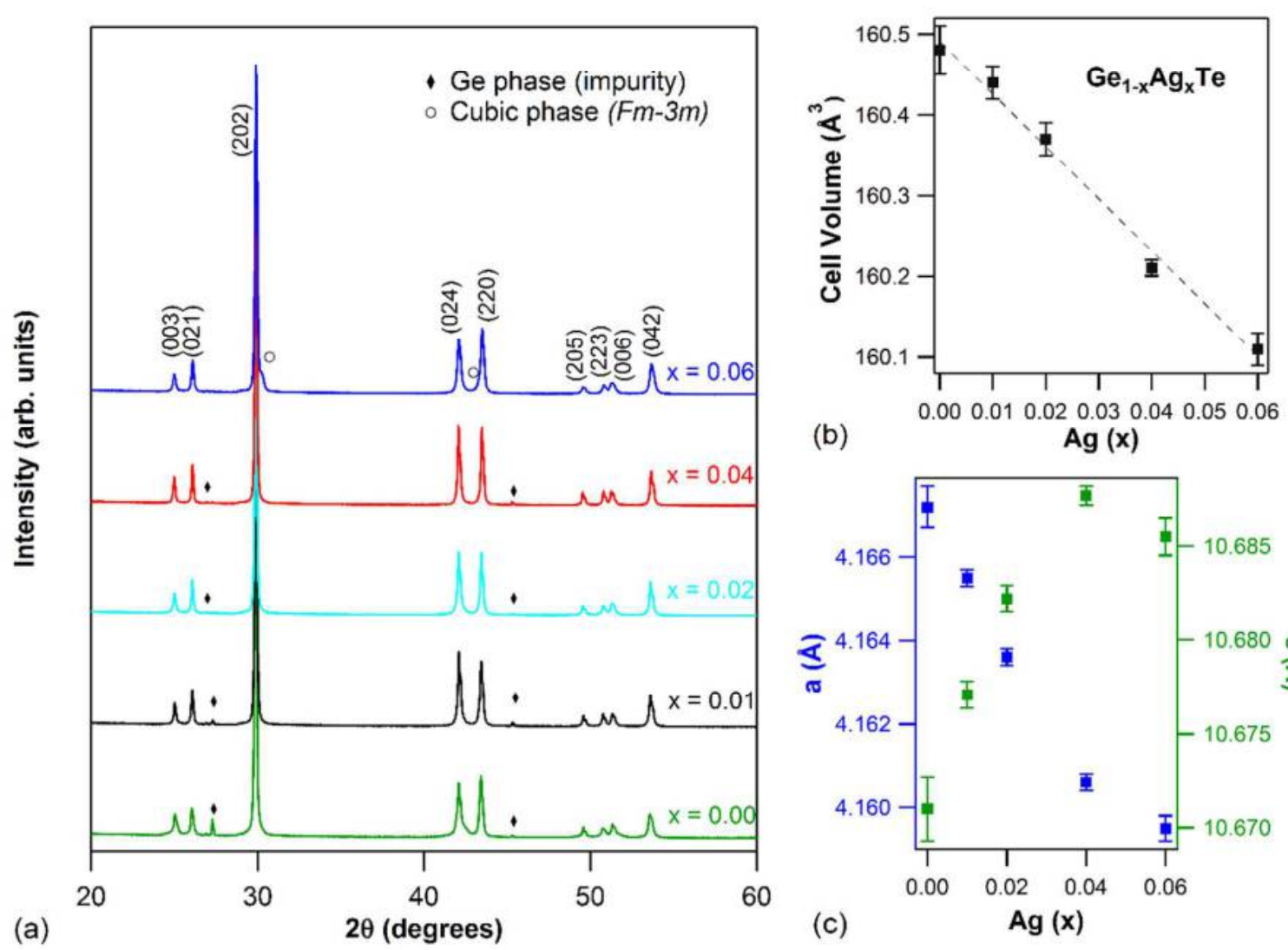

Figure 1. (a) Powder XRD patterns for $\mathrm{Ge}_{1-\mathrm{x}} A g_{x} T e$ samples, (b) hexagonal cell volume vs. Ag concentration, and (c) evolution of a and c lattice parameters with Ag content.

In our experimental conditions, the maximum solubility of silver in the rhombohedral GeTe phase appears to be between 4 and 6 mol\%, as a cubic phase ( $F m-3 m$ space group; $a=5.9118(9) \AA$ ) starts to appear for values of $x \geq 0.06$. This secondary cubic phase was identified as (Ag,Ge)Te, as the estimated lattice parameter is smaller than that of undoped cubic GeTe $(a=6,02 \AA)^{44,70}$. Microscopic data also supports the PXRD results (refer ESI + Figure S1). 
The electrical and thermal transport properties of $\mathrm{Ge}_{1-x} \mathrm{Ag}_{\mathrm{x}} \mathrm{Te}$ samples for the values of $x=0.00$ and 0.02 are pretty much close to $x=0.01$. Hence, for better visibility, only values of $x=0.01,0.04$ and 0.06 are depicted in the forthcoming graphs and sections. The room temperature values of carrier concentration (n) and mobility $(\mu)$ obtained from Hall measurements using equations (2) and (3) are reported in Table 1.

Table 1. Hall measurement results (at $300 \mathrm{~K}$ ) of carrier concentration, mobility, and computed effective mass for $\mathrm{Ge}_{1-\mathrm{x}} \mathrm{Ag}$ 斯 samples.

\begin{tabular}{|cccc|}
\hline $\boldsymbol{x}$ & Carrier Concentration, $\mathbf{n}$ & Mobility, $\boldsymbol{\mu}$ & Effective mass, $\mathbf{m}^{*}$ \\
& $\left(\mathrm{~cm}^{-3}\right)$ & $\left(\mathrm{cm}^{2} \mathrm{~V}^{-1} \mathrm{~s}^{-1}\right)$ & $\left(\mathrm{m}_{\mathrm{e}}\right)$ \\
0.01 & $1.39 \times 10^{21}$ & 31.7 & 1.84 \\
0.04 & $2.74 \times 10^{21}$ & 13.7 & 2.90 \\
0.06 & $2.52 \times 10^{22}$ & 1.89 & 12.71 \\
\hline
\end{tabular}

Holes are the major charge carriers ( $p$-type), as the Hall voltage is positive in these samples. The carrier concentration value at room temperature increases with increasing $\mathrm{Ag}$ content, due to the aliovalent $\mathrm{Ag}^{+}$at the $\mathrm{Ge}^{2+}$ site in $\mathrm{GeTe}$, which gives rise to extra mobile holes in the system. In pristine GeTe, a Ge vacancy has very low formation energy and is the most easily formed intrinsic defect ${ }^{52,53}$. The addition of $\mathrm{Ag}$ to GeTe can further decrease this vacancy formation energy, thereby leading to a large density of carrier concentrations. The temperature-dependent electrical transport properties of $\mathrm{Ge}_{1-\mathrm{x}} \mathrm{Ag}_{\mathrm{x}} \mathrm{Te}$ are shown in Figure 2. The electrical conductivity of all the samples decreases with increasing temperature (Figure 2a), which is the archetypal behavior of degenerate semi-conductors ${ }^{31,37,38,71}$. As expected, the room temperature hole mobility $(\mu)$ decreases with the increase in Ag concentration (Table 1 ) due to an alloy scattering mechanism, which usually comes into picture in such a case of doping ${ }^{31,33,72}$. Besides 
alloy scattering, the low $\mu$ in $\mathrm{Ge}_{0.94} \mathrm{Ag}_{0.06} \mathrm{Te}$ can also be attributed to the presence of an additional cubic phase.

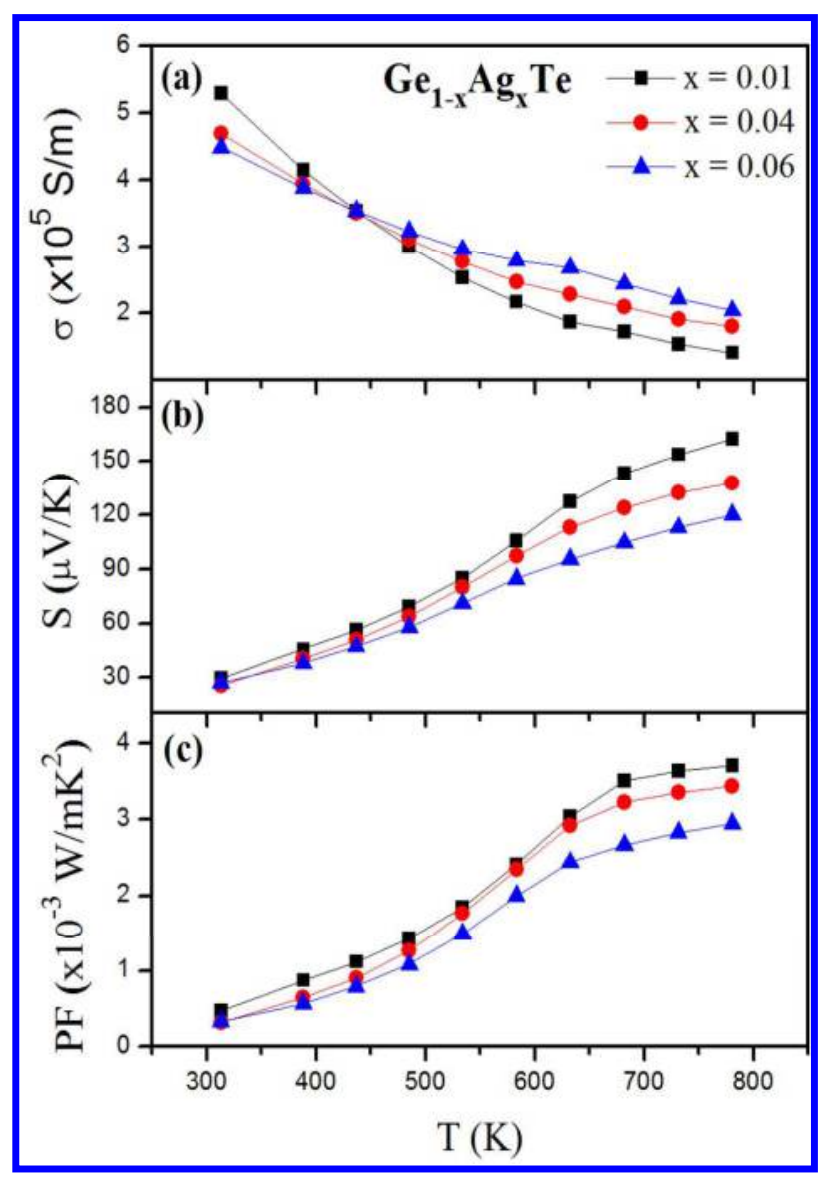

Figure 2. Temperature-dependent (a) electrical conductivity ( $\sigma$ ), (b) Seebeck coefficient, (S), (c) Power

$$
\text { factor }\left(P F=S^{2} \sigma\right) \text { of } G e_{1-x} A g_{x} T e(x=0.01-0.06) \text { solid-state solutions. }
$$

Figure $2 \mathrm{~b}$ shows the temperature-dependent Seebeck coefficient results. $\mathrm{S}$ values being positive for all the composition over the entire temperature range, indicates $p$-type charge carriers, which is consistent with the Hall measurement results. The thermopowers of $\mathrm{Ge}_{1-x} \mathrm{Ag}_{\mathrm{x}} \mathrm{Te}$ show a steadily increasing trend with temperature. With increased $\mathrm{Ag}$ content, the change in S values at room temperature is not much evident, but they decrease significantly with increasing temperature. At $773 \mathrm{~K}$, the $\mathrm{S}$ value for $\mathrm{Ge}_{0.99} \mathrm{Ag}_{0.01} \mathrm{Te}$ is $\sim 163 \mu \mathrm{V} / \mathrm{K}$. It reduces to $\sim 120 \mu \mathrm{V} / \mathrm{K}$ for $\mathrm{Ge}_{0.94} \mathrm{Ag}_{0.06} \mathrm{Te}$ at the same temperature. It is 
understood that the doping of $\mathrm{Ag}$ in GeTe decreases the $\mathrm{S}$ value, as it drastically inflates the free carrier concentration.

Mention must be made on the fact that the presence of minor proportion of secondary Ge phases (impurities) in the samples of $\mathrm{Ge}_{1-\mathrm{x}} \mathrm{Ag}_{\mathrm{x}} \mathrm{Te}(x=0.01$ to 0.04$)$ has no significant impact on its $\mathrm{TE}$ properties $^{36,37,41}$.

The temperature dependence of the power factors $\left(S^{2} \sigma\right)$ for $\mathrm{Ge}_{1-\mathrm{x}} \mathrm{Ag}_{\mathrm{x}} \mathrm{Te}$ are depicted in Figure $2 \mathrm{c}$. The sample with $x=0.01$ shows a power factor value of $\sim 0.47 \times 10^{-3} \mathrm{~W} / \mathrm{mK}^{2}$ at $310 \mathrm{~K}$, which rises to $\sim 3.7 \times 10^{-3}$ $\mathrm{W} / \mathrm{mK}^{2}$ at $773 \mathrm{~K}$, whereas the sample with $x=0.06$ exhibits a lower power factor values of $\sim 0.3 \times 10^{-3}$ $\mathrm{W} / \mathrm{mK}^{2}$ at $310 \mathrm{~K}$ and $\sim 2.9 \times 10^{-3} \mathrm{~W} / \mathrm{mK}^{2}$ at $773 \mathrm{~K}$. Reduction of Seebeck coefficient with Ag content due to local electron imbalance considerably affects the thermoelectric power factor.

Using the experimental data, the effective masses of $\mathrm{Ge}_{1-x} \mathrm{Ag}_{\mathrm{x}} \mathrm{Te}$ samples are estimated using equation (8) and are listed in Table 1 . The values of $\mathrm{m}^{*}$ given here are only an estimate, as the calculation considers only a single parabolic band for simplicity. Accurate evaluation of $\mathrm{m}^{*}$ for GeTe based materials is quite complex, as their conduction band structures are not only anisotropic (different along transverse and longitudinal directions) and non-parabolic, but also have a unique corrugated structure in the doping range near the band edges, which cannot be covered in the parabolic band models ${ }^{73} . \mathrm{m}^{*}$ increases gradually from $1.84 \mathrm{~m}_{\mathrm{e}}$ to $12.71 \mathrm{~m}_{\mathrm{e}}$ ( $\mathrm{m}_{\mathrm{e}}$ is the free electron mass) with increasing $\mathrm{Ag}$ concentration from 0 to $6 \%$ (Table 1$)$.

In order to study the effect of germanium substitution with silver in rhombohedral GeTe (r-GeTe), DFT calculations were carried out on $\mathrm{Ag}_{0.042} \mathrm{Ge}_{0.958} \mathrm{Te}$ model structure (as it is close to the experimental composition). Previous computational studies on amorphous and cubic GeTe (c-GeTe) showed that the formation energy (to form a defect) becomes lower when $\mathrm{Ag}$ atoms replace Ge ones ${ }^{74,75}$. The DOS computed for $\mathrm{r}-\mathrm{GeTe}$ and $\mathrm{Ag}_{0.042} \mathrm{Ge}_{0.958} \mathrm{Te}$ are sketched in Figure 3. 


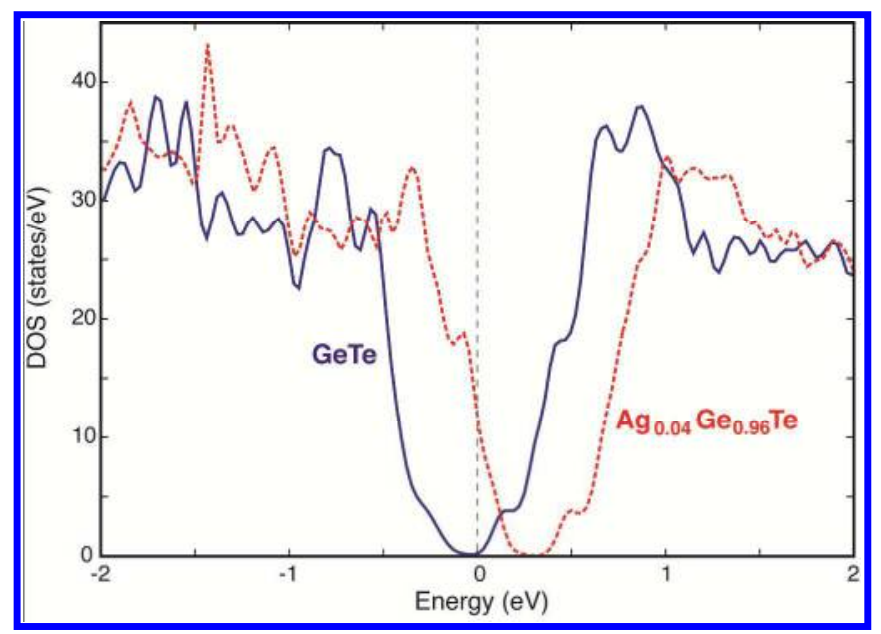

Figure 3. Computed DOS for r-GeTe and $\mathrm{Ag}_{0.04} \mathrm{Ge}_{0.96} \mathrm{Te}$ models. The Fermi energy level is set at $\mathrm{O} \mathrm{eV}$.

Substituting divalent Ge with monovalent $\mathrm{Ag}$ decreases the number of electrons and, assuming a rigid band model, shifts the Fermi level downwards. Therefore, the DOS at the Fermi level significantly increases in agreement with the enhancement of charge carrier density upon increase of the silver vs. germanium ratio in the solid solution. According to the Boltzmann equation, the carrier concentration and the Seebeck coefficient have an inverse relationship, so an improvement in one will result in a degradation of the other. This is consistent with the decrease of the Seebeck coefficient measured with the increase of silver content. Kanatzidis et al. showed that the electronic structure of c-GeTe is perturbed by impurities in the concentration range of $1 \%{ }^{55}$. As observed in Figure 4, upon substitution of Ge with Ag in r-GeTe, band degeneracy at the valence band maximum (VBM) and conduction band minimum (CBM) of the host material is removed and band splitting occurs in the presence of silver in GeTe. In the band structure of the $\mathrm{Ag}_{0.042} \mathrm{Ge}_{0.958} \mathrm{Te}$ model compound (Figure $4 \mathrm{~b}$ ), the Fermi level lies almost at the top of the valence band. This reinforces the decrease of the Seebeck coefficient with Ag content. 


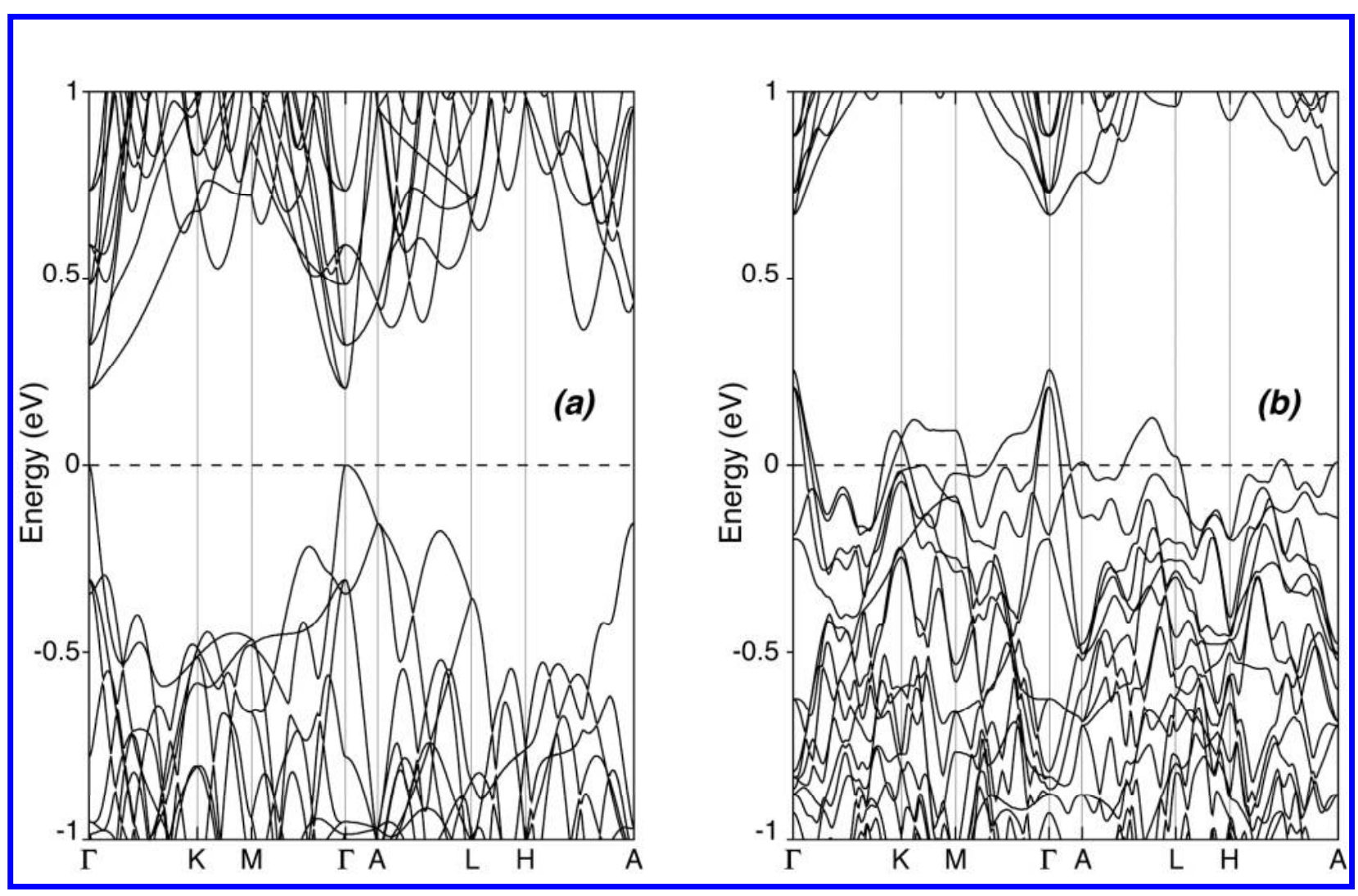

Figure 4. Electronic band structures of pristine r-GeTe (a) and $\mathrm{Ag}_{0.042} \mathrm{Ge}_{0.958} \mathrm{Te}(\mathrm{b})$. In order to compare the band structures, the same supercell has been considered for $r$-GeTe.

The gradual increase of $\mathrm{m}^{*}$ with increasing Ag concentration, as reported in Table 1 , probably results from the increasing contribution of several hole pockets in the valence band of $\mathrm{Ag}_{0.042} \mathrm{Ge}_{0.958} \mathrm{Te}$, as expected from its band structure. Isoelectronic $\mathrm{M}_{0.042} \mathrm{Ge}_{0.958} \mathrm{Te}(\mathrm{M}=\mathrm{Cu}, \mathrm{Au})$ compounds were studied in silico. As for the silver analog, substitution of one Ge by a group-11 transition metal hardly modifies the crystal structure of $r-G e T e . ~ D O S$ of $\mathrm{Cu}_{0.042} \mathrm{Ge}_{0.958} \mathrm{Te}$ and $\mathrm{Au}_{0.042} \mathrm{Ge}_{0.958} \mathrm{Te}$ models (Figure S4, ESI + ) look very similar to that of the silver analogue shown in Figure 3. In order to evaluate the impact of Ge substitution with group-11 elements, the electronic part of the transport properties was computed using a semi-classical approach. The Seebeck coefficient as a function of the chemical potential is shown in Figure 5. Irrespective of the carrier concentration, the Seebeck coefficient is higher for silver-doped 
GeTe compared to its gold and copper congeners. This is consistent with the DOS of $\mathrm{M}_{0.042} \mathrm{Ge}_{0.958} \mathrm{Te}(\mathrm{M}=$ $\mathrm{Cu}, \mathrm{Ag}, \mathrm{Au})$, as sketched in Figure S4 (ESIt).

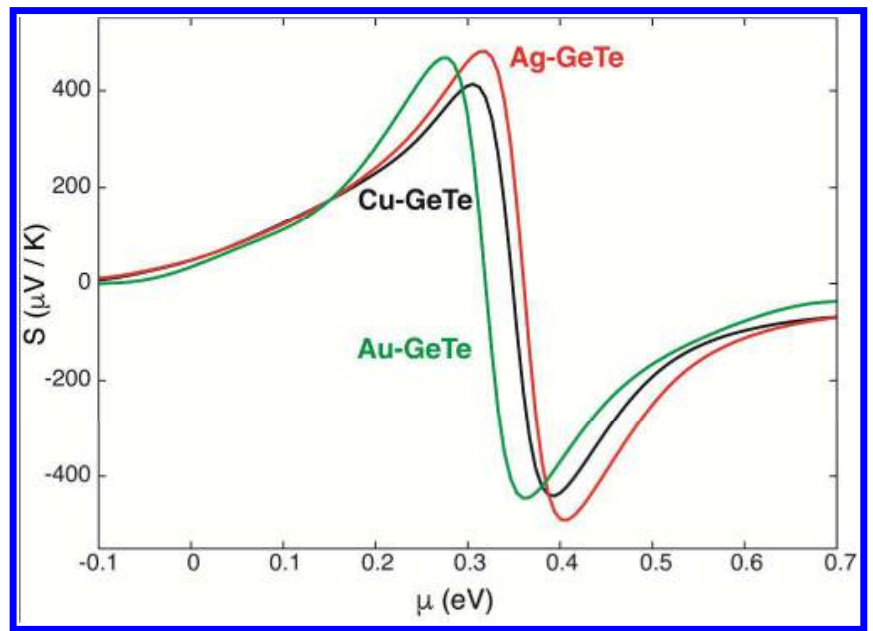

Figure 5. Seebeck coefficient as a function of the chemical potential ( $\mu$ ), computed at $300 \mathrm{~K}$ for

$$
M_{0.042} G e_{0.958} T e(M=C u, A g, A u) \text { using a semi-classical approach. }
$$

The temperature-dependent total thermal conductivity $\kappa_{\text {total }}$ derived from $D$ and $C_{p}$ using equation (5) is presented in Figure 6a. At $773 \mathrm{~K}$, the $\kappa_{\text {total }}$ value for $\mathrm{Ge}_{0.99} \mathrm{Ag}_{0.01} \mathrm{Te}$ is $\sim 3.05 \mathrm{~W} / \mathrm{mK}$ and with addition of more $\mathrm{Ag}$, it increases to $\sim 4.02 \mathrm{~W} / \mathrm{mK}$ for $\mathrm{Ge}_{0.94} \mathrm{Ag}_{0.06} \mathrm{Te}$. It is noteworthy that the $\kappa_{\text {total }}$ value for $\mathrm{Ge}_{0.99} \mathrm{Ag}_{0.01} \mathrm{Te}$ decreases till $673 \mathrm{~K}$ and then marginally increases. Such a change of trend was observed for other GeTe based materials, which was ascribed to the second-order phase transition from rhombohedral to cubic phase ${ }^{33,36,37,39,44}$. This transition temperature decreases from $673 \mathrm{~K}$ to $573 \mathrm{~K}$ with increase in Ag content from 1 to 6 mol\%.

To better understand the impacts of $\mathrm{Ag}$ on the thermal transport properties of GeTe, the contributions from electronic and lattice parts are calculated. The lattice thermal conductivity $\left(\kappa_{\text {latt }}\right)$ estimated from $\kappa_{\text {total }}$ by subtracting the electronic contribution $\left(\kappa_{\mathrm{e}}\right)$ via Wiedemann-Franz law, as in equation (9),

$$
\kappa_{e}=L \sigma T
$$


where $\kappa_{\mathrm{e}}$ is the electronic thermal conductivity and $\mathrm{L}$ is the Lorenz number computed by the condensed version of Single Parabolic Band model with acoustic phonon scattering (SPB-APS) ${ }^{76,77}$, as in equation (10)

$$
L=1.5+\exp \left[-\frac{|S|}{116}\right]
$$

where Seebeck coefficient $(S)$ is in $\mu \mathrm{VK}^{-1}$ and Lorenz number $(\mathrm{L})$ is in $10^{-8} \mathrm{~W} \Omega \mathrm{K}^{-2}$. The calculated temperature dependent Lorenz number for all the samples are in the range of $2.3 \times 10^{-8}$ to $1.75 \times 10^{-8}$ $\mathrm{W} \Omega \mathrm{K}^{-2}$ and is lower than the metallic limit of $2.45 \times 10^{-8} \mathrm{~W} \Omega \mathrm{K}^{-2}(\mathrm{ESI} t$, Figure $\mathrm{S} 3)$.

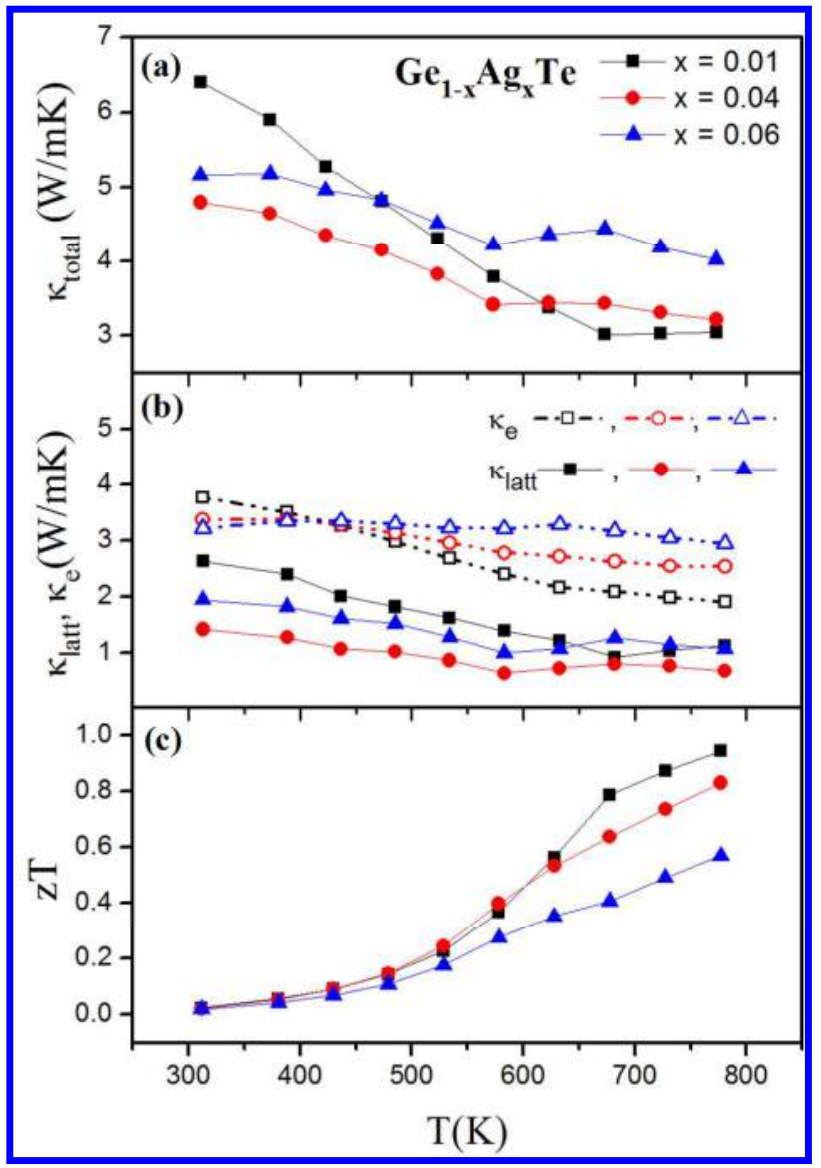

Figure 6. Temperature-dependent (a) total thermal conductivity $\left(\kappa_{\text {total }}\right)$, (b) lattice $\left(\kappa_{\text {latt }}\right)$ and electronic $\left(\kappa_{e}\right)$ thermal conductivities, (c) zT for $\mathrm{Ge}_{1-x} A g_{x} T e(x=0.01-0.06)$ solid-state solutions. 
The lattice and electronic thermal conductivities are plotted in Figure $6 \mathrm{~b}$. As it can be seen, the lattice contribution is relatively low compared to the electronic contribution, and at higher temperatures $\kappa_{\text {latt }}$ is in the order of $\sim 1 \mathrm{~W} / \mathrm{mK}$, analogous with that of other high performance GeTe based materials ${ }^{33,36-}$ 40,51,59,78,79 and other state of the art thermoelectric materials like PbTe ${ }^{13,71,80-91}$ and SnTe ${ }^{18,21,77,92-94}$. Ag substitution helps reducing this lattice contribution, presumably because of increased alloy scattering and phonon interfacial scattering at the grain boundaries. It is in fact the electronic part that affects the total thermal conductivity. At $773 \mathrm{~K}, \kappa_{\mathrm{e}}$ increases conspicuously with Ag doping, thereby contributing to the substantial raise in $\kappa_{\text {total }}$. More metallic behavior of Ag unfavorably affects the thermal conductivity of GeTe solid-state solutions.

The thermoelectric figure of merit $\mathrm{zT}$ as a function of temperature, calculated from the electrical transport and thermal conductivity data, as in equation (1) is shown in Figure $6 \mathrm{c}$. The maximum zT achieved is $\sim 0.95$ at $773 \mathrm{~K}$ for $\mathrm{Ge}_{0.99} \mathrm{Ag}_{0.01} \mathrm{Te}$, which is almost the same as pristine $\mathrm{GeTe}^{44}$. $\mathrm{zT}$ reduces to $\sim 0.57$ at $773 \mathrm{~K}$ for $\mathrm{Ge}_{0.94} \mathrm{Ag}_{0.06} \mathrm{Te}$. $\mathrm{Ag}$ insertion subsides the thermoelectric performance in GeTe mainly due to reduced Seebeck coefficient, arising due to proliferation of the hole concentration. This explains why $\mathrm{Ag}+\mathrm{Sb}$ pair substituted $\mathrm{Ag}_{x} \mathrm{Sb}_{x} \mathrm{Ge}_{50-2 x} \mathrm{Te}_{50}$ (TAGS) exhibits exceptional thermoelectric properties, as the opposing effects of excess hole concentration created by $\mathrm{Ag}$ (acceptor) insertion is compensated by $\mathrm{Sb}$ (donor dopant).

\section{Conclusion}

The crystalline ingots of $\mathrm{Ge}_{1-\mathrm{x}} \mathrm{Ag}_{\mathrm{x}} \mathrm{Te}(\mathrm{x}=0.00-0.06)$ have been synthesized by vacuum-sealed tube melting process. The solubility of $\mathrm{Ag}$ in $\mathrm{r}-\mathrm{GeTe}$ was found to be less than $6 \%$. Substitution of $\mathrm{Ge}$ by $\mathrm{Ag}$ profoundly affects the electronic and thermal transport properties of $r$-GeTe: (i) it proliferates the charge carrier density due to the aliovalent $\mathrm{Ag}^{+}$and the reduction in Ge vacancy formation energy, (ii) it 
lowers the Fermi level which lies almost at the top of the valence band, affecting the Seebeck coefficient, (iii) it leads to a loss of band degeneracy, (iv) it also leads to a surge in the contribution of several hole pockets in the valence band, thus increasing the effective mass, and ( $v$ ) it causes a decrease of the lattice thermal conductivity due to alloy scattering contributing to reduced mobility, but an increase of the electronic thermal conductivity. $\mathrm{Ge}_{1-\mathrm{x}} \mathrm{Ag}_{\mathrm{x}} \mathrm{Te}(x \leq 0.04)$ exhibits a mean $\mathrm{zT} \sim 0.85$ at $773 \mathrm{~K}$. First-principles calculations carried out on GeTe substituted with other coinage metals (Cu, $\mathrm{Au}$ ), demonstrate that silver doped solid solutions exhibit higher thermopower compared to the others. The multiple factors presented in this work demonstrate that substitution by just a coinage metal is not the best choice of a dopant for achieving high $\mathrm{zT}$ in GeTe-based thermoelectric materials, and reiterates the need for pair substitution, as like in TAGS where silver and antimony substitute for germanium, to enhance the figure-of-merit of GeTe.

\title{
Supporting Information
}

Microstructure, Thermal Diffusivity, Lorenz number, and DOS calculations.

\section{Author Contributions}

The manuscript was written through contributions of all authors. All authors have given approval to the final version of the manuscript.

\author{
Notes \\ The authors declare no competing financial interest.
}




\section{Acknowledgement}

The European Commissions' Horizon 2020 research and innovation program under Marie SkłodowskaCurie GA. 642557 (CoACH-ITN) is gratefully acknowledged for the financial support. Sylvain Tricot (IPR, Rennes) is thanked for Hall measurements. B.S. thanks Manon Louazel (ENSCl, Limoges) and Rémy Baniel (UR1, Rennes) for their short internships.

\section{References}

(1) Vaqueiro, P.; Powell, A. V. Recent Developments in Nanostructured Materials for HighPerformance Thermoelectrics. J. Mater. Chem. 2010, 20, 9577-9584.

(2) Sootsman, J. R.; Chung, D. Y.; Kanatzidis, M. G. New and Old Concepts in Thermoelectric Materials. Angew. Chem.Int.Ed. 2009, 48, 8616-8639.

(3) Kumar, A.; Walder, B. J.; Kunhi Mohamed, A.; Hofstetter, A.; Srinivasan, B.; Rossini, A. J.; Scrivener, K.; Emsley, L.; Bowen, P. The Atomic-Level Structure of Cementitious Calcium Silicate Hydrate. L.Phvs. Chem. C 2017, 121, 17188-17196.

(4) Jacobson, A. J. Materials for Solid Oxide Fuel Cells. Chem. Mater. 2010, 22, 660-674.

(5) Grätzel, M. Recent Advances in Sensitized Mesoscopic Solar Cells. Acc. Chem. Res. 2009, 42, 1788-1798.

(6) Liu, C.; Li, F.; Ma, L.-P.; Cheng, H.-M. Advanced Materials for Energy Storage. Adv. Mater. 2010, 22, E28-E62.

(7) LaLonde, A. D.; Pei, Y.; Wang, H.; Jeffrey Snyder, G. Lead Telluride Alloy Thermoelectrics. Mater. Todav 2011, 14, 526-532.

(8) Li, J.-F.; Liu, W.-S.; Zhao, L.-D.; Zhou, M. High-Performance Nanostructured Thermoelectric Materials. NPG Asia Mater. 2010, 2, 152-158.

(9) Ma, Y.; Hao, Q.; Poudel, B.; Lan, Y.; Yu, B.; Wang, D.; Chen, G.; Ren, Z. Enhanced Thermoelectric Figure-of-Merit in P-Type Nanostructured Bismuth Antimony Tellurium Alloys Made from Elemental Chunks. Nano Lett. 2008, 8, 2580-2584.

(10) Hicks, L. D.; Dresselhaus, M. S. Effect of Quantum-Well Structures on the Thermoelectric Figure of Merit. Phvs. Rev. B 1993, 47, 12727-12731.

(11) Sootsman, J. R.; Kong, H.; Uher, C.; D’Angelo, J. J.; Wu, C.-I.; Hogan, T. P.; Caillat, T.; Kanatzidis, M. G. Large Enhancements in the Thermoelectric Power Factor of Bulk PbTe at High Temperature by Synergistic Nanostructuring. Angew. Chem. Int. Ed. 2008, 47, 8618-8622.

(12) Biswas, K.; He, J.; Blum, I. D.; Wu, C.-I.; Hogan, T. P.; Seidman, D. N.; Dravid, V. P.; Kanatzidis, M. G. High-Performance Bulk Thermoelectrics with All-Scale Hierarchical Architectures. Nature 2012, 489, 414-418.

(13) Poudeu, P. F. P.; D’Angelo, J.; Downey, A. D.; Short, J. L.; Hogan, T. P.; Kanatzidis, M. G. High Thermoelectric Figure of Merit and Nanostructuring in Bulk P-Type $\mathrm{Na}_{1-x} \mathrm{~Pb}_{\mathrm{m}} \mathrm{Sb}_{\mathrm{y}} \mathrm{Te}_{\mathrm{m}+2}$. Anqew. Chem. Int. Ed. 2006, 45, 3835-3839. 
(14) Biswas, K.; He, J.; Zhang, Q.; Wang, G.; Uher, C.; Dravid, V. P.; Kanatzidis, M. G. Strained Endotaxial Nanostructures with High Thermoelectric Figure of Merit. Nat. Chem. 2011, 3, 160166.

(15) Cook, B. A.; Kramer, M. J.; Harringa, J. L.; Han, M.-K.; Chung, D.-Y.; Kanatzidis, M. G. Analysis of Nanostructuring in High Figure-of-Merit $\mathrm{Ag}_{1-\mathrm{x}} \mathrm{Pb}_{\mathrm{m}} \mathrm{SbTe}_{2+\mathrm{m}}$ Thermoelectric Materials. $\underline{\text { Adv. Funct. }}$ Mater. 2009, 19, 1254-1259.

(16) Poudeu, P. F. P.; Guéguen, A.; Wu, C.-I.; Hogan, T.; Kanatzidis, M. G. High Figure of Merit in Nanostructured $\mathrm{N}-\mathrm{Typ}_{\mathrm{p}} \mathrm{KPb}_{\mathrm{m}} \mathrm{SbTe}_{\mathrm{m}+2}$ Thermoelectric Materials. Chem. Mater. 2010, 22, 10461053.

(17) Zide, J. M. O.; Vashaee, D.; Bian, Z. X.; Zeng, G.; Bowers, J. E.; Shakouri, A.; Gossard, A. C. Demonstration of Electron Filtering to Increase the Seebeck Coefficient in InGaAs/InGaAlAs Superlattices. Phvs. Rev. B 2006, 74, 205335.

(18) Banik, A.; Shenoy, U. S.; Anand, S.; Waghmare, U. V.; Biswas, K. Mg Alloying in SnTe Facilitates Valence Band Convergence and Optimizes Thermoelectric Properties. Chem. Mater. 2015, 27, 581-587.

(19) Pei, Y.; Shi, X.; LaLonde, A.; Wang, H.; Chen, L.; Snyder, G. J. Convergence of Electronic Bands for High Performance Bulk Thermoelectrics. Nature 2011, 473, 66-69.

(20) Banik, A.; Shenoy, U. S.; Saha, S.; Waghmare, U. V.; Biswas, K. High Power Factor and Enhanced Thermoelectric Performance of SnTe-AgInTe $e_{2}$ : Synergistic Effect of Resonance Level and Valence Band Convergence. J. Am. Chem. Soc. 2016, 138, 13068-13075.

(21) Zhang, Q.; Liao, B.; Lan, Y.; Lukas, K.; Liu, W.; Esfarjani, K.; Opeil, C.; Broido, D.; Chen, G.; Ren, Z. High Thermoelectric Performance by Resonant Dopant Indium in Nanostructured SnTe. Proc. Natl. Acad. Sci. U. S. A. 2013, 110, 13261-13266.

(22) Carruthers, P. Theory of Thermal Conductivity of Solids at Low Temperatures. Rev. Mod. Phys. 1961, 33, 92-138.

(23) Srinivasan, B.; Gucci, F.; Boussard-Pledel, C.; Cheviré, F.; Reece, M. J.; Tricot, S.; Calvez, L.; Bureau, B. Enhancement in Thermoelectric Performance of N-Type Pb-Deficit Pb-Sb-Te Alloys. J. Allovs Compd. 2017, 729, 198-202.

(24) Zhao, W.; Wei, P.; Zhang, Q.; Dong, C.; Liu, L.; Tang, X. Enhanced Thermoelectric Performance in Barium and Indium Double-Filled Skutterudite Bulk Materials via Orbital Hybridization Induced by Indium Filler. J. Am. Chem. Soc. 2009, 131, 3713-3720.

(25) Brown, S. R.; Kauzlarich, S. M.; Gascoin, F.; Snyder, G. J. Yb ${ }_{14} \mathrm{MnSb}_{11}$ : New High Efficiency Thermoelectric Material for Power Generation. Chem. Mater. 2006, 18, 1873-1877.

(26) Toberer, E. S.; May, A. F.; Snyder, G. J. Zintl Chemistry for Designing High Efficiency Thermoelectric Materials. Chem. Mater. 2010, 22, 624-634.

(27) Kauzlarich, S. M.; Brown, S. R.; Snyder, G. J. Zintl Phases for Thermoelectric Devices. Dalton Trans. 2007, No. 21, 2099-2107.

(28) Venkatasubramanian, R.; Siivola, E.; Colpitts, T.; O’Quinn, B. Thin-Film Thermoelectric Devices with High Room-Temperature Figures of Merit. Nature 2001, 413, 597-602.

(29) Lucas, P.; Conseil, C.; Yang, Z.; Hao, Q.; Cui, S.; Boussard-Pledel, C.; Bureau, B.; Gascoin, F.; Caillaud, C.; Gulbiten, O.; et al. Thermoelectric Bulk Glasses Based on the Cu-As-Te-Se System. J. Mater. Chem. A 2013, 1, 8917-8925.

(30) Gonçalves, A. P.; Lopes, E. B.; Rouleau, O.; Godart, C. Conducting Glasses as New Potential Thermoelectric Materials: The Cu-Ge-Te Case. J. Mater. Chem. 2010, 20, 1516-1521.

(31) Srinivasan, B.; Boussard-Pledel, C.; Dorcet, V.; Samanta, M.; Biswas, K.; Lefèvre, R.; Gascoin, F.; Cheviré, F.; Tricot, S.; Reece, M.; et al. Thermoelectric Properties of Highly-Crystallized Ge-Te-Se Glasses Doped with Cu/Bi. Materials 2017, 10, 328. 
(32) Srinivasan, B.; Cui, S.; Prestipino, C.; Gellé, A.; Boussard-Pledel, C.; Ababou-Girard, S.; Trapananti, A.; Bureau, B.; Di Matteo, S. Possible Mechanism for Hole Conductivity in Cu-As-Te Thermoelectric Glasses: A XANES and EXAFS Study. L.Phvs. Chem. C 2017, 121, 14045-14050.

(33) Gelbstein, Y.; Davidow, J. Highly Efficient Functional GexPb ${ }_{1-x} T e$ Based Thermoelectric Alloys. Phvs. Chem. Chem. Phvs. 2014, 16, 20120-20126.

(34) Gelbstein, Y.; Davidow, J.; Girard, S. N.; Chung, D. Y.; Kanatzidis, M. Controlling Metallurgical Phase Separation Reactions of the $\mathrm{Ge}_{0.87} \mathrm{~Pb}_{0.13}$ Te Alloy for High Thermoelectric Performance. $A d v$. Enerav Mater. 2013, 3, 815-820.

(35) Hazan, E.; Ben-Yehuda, O.; Madar, N.; Gelbstein, Y. Functional Graded Germanium-Lead Chalcogenide-Based Thermoelectric Module for Renewable Energy Applications. Adv. Enerav Mater. 2015, 5, 1500272.

(36) Wu, D.; Zhao, L.-D.; Hao, S.; Jiang, Q.; Zheng, F.; Doak, J. W.; Wu, H.; Chi, H.; Gelbstein, Y.; Uher, C.; et al. Origin of the High Performance in GeTe-Based Thermoelectric Materials upon $\mathrm{Bi}_{2} \mathrm{Te}_{3}$ Doping. L.Am. Chem. Soc. 2014, 136, 11412-11419.

(37) Perumal, S.; Roychowdhury, S.; Negi, D. S.; Datta, R.; Biswas, K. High Thermoelectric Performance and Enhanced Mechanical Stability of P-Type $\mathrm{Ge}_{1-\mathrm{x}} \mathrm{Sb}_{\mathrm{x}} \mathrm{Te}$. Chem. Mater. 2015, 27, 7171-7178.

(38) Perumal, S.; Roychowdhury, S.; Biswas, K. Reduction of Thermal Conductivity through Nanostructuring Enhances the Thermoelectric Figure of Merit in $\mathrm{Ge}_{1-x} \mathrm{Bi}_{x} \mathrm{Te}$. Inorg. Chem. Front. 2016, 3, 125-132.

(39) Lee, J. K.; Oh, M. W.; Kim, B. S.; Min, B. K.; Lee, H. W.; Park, S. D. Influence of Mn on Crystal Structure and Thermoelectric Properties of GeTe Compounds. Electron. Mater. Lett. 2014, 10, 813-817.

(40) Gelbstein, Y.; Dado, B.; Ben-Yehuda, O.; Sadia, Y.; Dashevsky, Z.; Dariel, M. P. High Thermoelectric Figure of Merit and Nanostructuring in Bulk P-Type $\mathrm{Ge}_{\mathrm{x}}\left(\mathrm{Sn}_{\mathrm{y}} \mathrm{Pb}_{1-\mathrm{y}}\right)_{1-\mathrm{x}} \mathrm{Te}$ Alloys Following a Spinodal Decomposition Reaction. Chem. Mater. 2010, 22, 1054-1058.

(41) Wu, L.; Li, X.; Wang, S.; Zhang, T.; Yang, J.; Zhang, W.; Chen, L.; Yang, J. Resonant Level-Induced High Thermoelectric Response in Indium-Doped GeTe. NPG Asia Mater. 2017, 9, e343.

(42) Yang, S. H.; Zhu, T. J.; Sun, T.; He, J.; Zhang, S. N.; Zhao, X. B. Nanostructures in High-Performance $(\mathrm{GeTe})_{x}\left(\mathrm{AgSbTe}_{2}\right)_{100-x}$ Thermoelectric Materials. Nanotechnoloav 2008, 19, 245707.

(43) Cook, B. A.; Kramer, M. J.; Wei, X.; Harringa, J. L.; Levin, E. M. Nature of the Cubic to Rhombohedral Structural Transformation in $\left(\mathrm{AgSbTe}_{2}\right)_{15}(\mathrm{GeTe})_{85}$ Thermoelectric Material. J. Appl. Phvs. 2007, 101, 053715.

(44) Perumal, S.; Roychowdhury, S.; Biswas, K. High Performance Thermoelectric Materials and Devices Based on GeTe. J. Mater. Chem. C 2016, 4, 7520-7536.

(45) Rosi, F. D.; Dismukes, J. P.; Hockings, E. F. Semiconductor Materials for Thermoelectric Power Generation up to 700 C. Electr. Ena. 1960, 79, 450-459.

(46) Schröder, T.; Schwarzmüller, S.; Stiewe, C.; de Boor, J.; Hölzel, M.; Oeckler, O. The Solid Solution Series $(\mathrm{GeTe})_{\mathbf{x}}\left(\mathrm{LiSbTe}_{2}\right)_{2}(1 \leq \mathrm{X} \leq 11)$ and the Thermoelectric Properties of $(\mathrm{GeTe})_{11}\left(\mathrm{LiSbTe}_{2}\right)_{2}$. Inora. Chem. 2013, 52, 11288-11294.

(47) Schröder, T.; Rosenthal, T.; Giesbrecht, N.; Maier, S.; Scheidt, E.-W.; Scherer, W.; Snyder, G. J.; Schnick, W.; Oeckler, O. TAGS-Related Indium Compounds and Their Thermoelectric Properties the Solid Solution Series $(\mathrm{GeTe})_{\mathrm{X}} \mathrm{AgIn}_{\mathrm{y}} \mathrm{Sb}_{1-\mathrm{y}} \mathrm{Te}_{2}(\mathrm{X}=1-12 ; \mathrm{Y}=0.5$ and 1). J.Mater. Chem. A 2014, 2 , 6384-6395.

(48) Shi, X.; Salvador, J. R.; Yang, J.; Wang, H. Prospective Thermoelectric Materials: $\left(\mathrm{AgSbTe}_{2}\right)_{100-x}$ (SnTe) X Quaternary System (X = 80, 85, 90, and 95). Sci. Adv. Mater. 2011, 3, 667-671.

(49) Levin, E. M.; Hanus, R.; Hanson, M.; Straszheim, W. E.; Schmidt-Rohr, K. Thermoelectric Properties of $\mathrm{Ag}_{2} \mathrm{Sb}_{2} \mathrm{Ge}_{46-\mathrm{x}} \mathrm{Dy} \mathrm{T}_{\mathrm{x}} \mathrm{Te}_{50}$ Alloys with High Power Factor. Phys. Status Solidi A 2013, 210 , 2628-2637. 
(50) Fahrnbauer, F.; Souchay, D.; Wagner, G.; Oeckler, O. High Thermoelectric Figure of Merit Values of Germanium Antimony Tellurides with Kinetically Stable Cobalt Germanide Precipitates. J. Am. Chem. Soc. 2015, 137, 12633-12638.

(51) Rosenthal, T.; Schneider, M. N.; Stiewe, C.; Döblinger, M.; Oeckler, O. Real Structure and Thermoelectric Properties of GeTe-Rich Germanium Antimony Tellurides. Chem. Mater. 2011, 23, 4349-4356.

(52) Levin, E. M. Effects of Ge Substitution in GeTe by Ag or Sb on the Seebeck Coefficient and Carrier Concentration Derived from ${ }^{125}$ Te NMR. Phvs. Rev. B 2016, 93, 045209.

(53) Edwards, A. H.; Pineda, A. C.; Schultz, P. A.; Martin, M. G.; Thompson, A. P.; Hjalmarson, H. P.; Umrigar, C. J. Electronic Structure of Intrinsic Defects in Crystalline Germanium Telluride. Phys. Rev. B 2006, 73, 045210.

(54) Rabe, K. M.; Joannopoulos, J. D. Theory of the Structural Phase Transition of GeTe. Phys. Rev. B 1987, 36, 6631-6639.

(55) Hoang, K.; Mahanti, S. D.; Kanatzidis, M. G. Impurity Clustering and Impurity-Induced Bands in PbTe-, SnTe-, and GeTe-Based Bulk Thermoelectrics. Phvs. Rev. B 2010, 81, 115106.

(56) Li, J.; Chen, Z.; Zhang, X.; Sun, Y.; Yang, J.; Pei, Y. Electronic Origin of the High Thermoelectric Performance of GeTe among the P-Type Group IV Monotellurides. NPG Asia Mater. 2017, 9, e353.

(57) Rodríguez-Carvajal, J. Recent Advances in Magnetic Structure Determination by Neutron Powder Diffraction. Phvs. B Condens. Matter 1993, 192, 55-69.

(58) Li, J.; Zhang, X.; Lin, S.; Chen, Z.; Pei, Y. Realizing the High Thermoelectric Performance of GeTe by Sb-Doping and Se-Alloying. Chem. Mater. 2017, 29, 605-611.

(59) Schröder, T.; Rosenthal, T.; Giesbrecht, N.; Nentwig, M.; Maier, S.; Wang, H.; Snyder, G. J.; Oeckler, O. Nanostructures in Te/Sb/Ge/Ag (TAGS) Thermoelectric Materials Induced by Phase Transitions Associated with Vacancy Ordering. Inora. Chem. 2014, 53, 7722-7729.

(60) Clark, S. J.; Segall, M. D.; Pickard, C. J.; Hasnip, P. J.; Probert, M. I. J.; Refson, K.; Payne, M. C. First Principles Methods Using CASTEP. Z. Für Krist. - Cryst. Mater. 2009, 220, 567-570.

(61) Perdew, J. P.; Burke, K.; Ernzerhof, M. Generalized Gradient Approximation Made Simple. Phys. Rev.Lett. 1996, 77, 3865-3868.

(62) Tkatchenko, A.; Scheffler, M. Accurate Molecular Van Der Waals Interactions from Ground-State Electron Density and Free-Atom Reference Data. Phys. Rev. Lett. 2009, 102, 073005.

(63) Monkhorst, H. J.; Pack, J. D. Special Points for Brillouin-Zone Integrations. Phvs. Rev. B 1976, 13, 5188-5192.

(64) Blaha, P.; Schwarz, K.; Madsen, G.; Kvasnicka, D.; Luitz, J. WIEN2K: An Augmented Plane Wave plus Local Orbitals Program for Calculating Crystal Properties; Karlheinz Schwarz, Techn. Universität Wien, Austria: Wien, Austria, 2001.

(65) May, A. F.; Toberer, E. S.; Saramat, A.; Snyder, G. J. Characterization and Analysis of Thermoelectric Transport in n-type $\mathrm{Ba}_{8} \mathrm{Ga}_{16-\mathrm{x}} \mathrm{Ge}_{30+x}$. Phvs. Rev. B 2009, 80, 125205.

(66) Toberer, E. S.; Zevalkink, A.; Crisosto, N.; Snyder, G. J. The Zintl Compound $\mathrm{Ca}_{5} \mathrm{Al}_{2} \mathrm{Sb}_{6}$ for Low-Cost Thermoelectric Power Generation. Adv. Funct. Mater. 2010, 20, 4375-4380.

(67) Scheidemantel, T. J.; Ambrosch-Draxl, C.; Thonhauser, T.; Badding, J. V.; Sofo, J. O. Transport Coefficients from First-Principles Calculations. Phys. Rev. B 2003, 68, 125210.

(68) Madsen, G. K. H. Automated Search for New Thermoelectric Materials: The Case of LiZnSb. J. Am. Chem. Soc. 2006, 128, 12140-12146.

(69) Madsen, G. K. H.; Singh, D. J. BoltzTraP. A Code for Calculating Band-Structure Dependent Quantities. Comput. Phvs. Commun. 2006, 175, 67-71. 
(70) Wiedemeier, H.; Siemers, P. A. The Temperature-Composition Phase Diagram of the GeSeGeTe System. In Modern High Temperature Science; Margrave, J. L., Ed.; Humana Press, 1984; pp 395-408. https://doi.org/10.1007/978-1-4612-5180-4 23

(71) LaLonde, A. D.; Pei, Y.; Snyder, G. J. Reevaluation of $\mathrm{PbTe}_{1-\mathrm{x}} \mathrm{I}_{\mathrm{x}}$ as High Performance N-Type Thermoelectric Material. Energv Environ. Sci. 2011, 4, 2090-2096.

(72) Wang, H.; LaLonde, A. D.; Pei, Y.; Snyder, G. J. The Criteria for Beneficial Disorder in Thermoelectric Solid Solutions. Adv. Funct. Mater. 2013, 23, 1586-1596.

(73) Chen, X.; Parker, D.; Singh, D. J. Importance of Non-Parabolic Band Effects in the Thermoelectric Properties of Semiconductors. Sci. Rep. 2013, 3, 3168.

(74) Xu, L.; Li, Y.; Yu, N. N.; Zhong, Y. P.; Miao, X. S. Local Order Origin of Thermal Stability Enhancement in Amorphous Ag Doping GeTe. Appl. Phvs. Lett. 2015, 106, 031904.

(75) Bruns, G.; Merkelbach, P.; Schlockermann, C.; Salinga, M.; Wuttig, M.; Happ, T. D.; Philipp, J. B.; Kund, M. Nanosecond Switching in GeTe Phase Change Memory Cells. Appl. Phys. Lett. 2009, 95, 043108.

(76) Kim, H.-S.; Gibbs, Z. M.; Tang, Y.; Wang, H.; Snyder, G. J. Characterization of Lorenz Number with Seebeck Coefficient Measurement. APL Mater. 2015, 3, 041506.

(77) Zhang, L.; Wang, J.; Cheng, Z.; Sun, Q.; Li, Z.; Dou, S. Lead-Free SnTe-Based Thermoelectrics: Enhancement of Thermoelectric Performance by Doping with Gd/Ag. J. Mater. Chem. A 2016, 4, 7936-7942.

(78) Davidow, J.; Gelbstein, Y. A Comparison Between the Mechanical and Thermoelectric Properties of Three Highly Efficient P-Type GeTe-Rich Compositions: TAGS-80, TAGS-85, and 3\% $\mathrm{Bi}_{2} \mathrm{Te}_{3}$ Doped $\mathrm{Ge}_{0.87} \mathrm{~Pb}_{0.13}$ Te. J. Electron. Mater. 2013, 42, 1542-1549.

(79) Welzmiller, S.; Rosenthal, T.; Ganter, P.; Neudert, L.; Fahrnbauer, F.; Urban, P.; Stiewe, C.; Boor, J. de; Oeckler, O. Layered Germanium Tin Antimony Tellurides: Element Distribution, Nanostructures and Thermoelectric Properties. Dalton Trans. 2014, 43, 10529-10540.

(80) Bali, A.; Wang, H.; Snyder, G. J.; Mallik, R. C. Thermoelectric Properties of Indium Doped PbTe ${ }_{y} \mathrm{Se}_{\mathrm{y}}$ Alloys. J. Appl. Phys. 2014, 116, 033707.

(81) Zhang, Q.; Wang, H.; Zhang, Q.; Liu, W.; Yu, B.; Wang, H.; Wang, D.; Ni, G.; Chen, G.; Ren, Z. Effect of Silicon and Sodium on Thermoelectric Properties of Thallium-Doped Lead Telluride-Based Materials. Nano Lett. 2012, 12, 2324-2330.

(82) Zhang, Q.; Wang, H.; Liu, W.; Wang, H.; Yu, B.; Zhang, Q.; Tian, Z.; Ni, G.; Lee, S.; Esfarjani, K.; et al. Enhancement of Thermoelectric Figure-of-Merit by Resonant States of Aluminium Doping in Lead Selenide. Enerav Environ. Sci. 2012, 5, 5246-5251.

(83) Yu, B.; Zhang, Q.; Wang, H.; Wang, X.; Wang, H.; Wang, D.; Wang, H.; Snyder, G. J.; Chen, G.; Ren, Z. F. Thermoelectric Property Studies on Thallium-Doped Lead Telluride Prepared by Ball Milling and Hot Pressing. J. Appl. Phvs. 2010, 108, 016104.

(84) Zhang, Q.; Cao, F.; Lukas, K.; Liu, W.; Esfarjani, K.; Opeil, C.; Broido, D.; Parker, D.; Singh, D. J.; Chen, G.; et al. Study of the Thermoelectric Properties of Lead Selenide Doped with Boron, Gallium, Indium, or Thallium. J. Am. Chem. Soc. 2012, 134, 17731-17738.

(85) Zhang, Q.; Yang, S.; Zhang, Q.; Chen, S.; Liu, W.; Wang, H.; Tian, Z.; Broido, D.; Gang Chen; Ren, Z. Effect of Aluminum on the Thermoelectric Properties of Nanostructured PbTe. Nanotechnologv 2013, 24, 345705.

(86) Poudeu, P. F. P.; D’Angelo, J.; Kong, H.; Downey, A.; Short, J. L.; Pcionek, R.; Hogan, T. P.; Uher, C.; Kanatzidis, M. G. Nanostructures versus Solid Solutions: Low Lattice Thermal Conductivity and Enhanced Thermoelectric Figure of Merit in $\mathrm{Pb}_{9.6} \mathrm{Sb}_{0.2} \mathrm{Te}_{10-x} \mathrm{Se}_{x}$ Bulk Materials. J. Am. Chem. Soc. 2006, 128, 14347-14355. 
(87) Zhang, Q.; Cao, F.; Liu, W.; Lukas, K.; Yu, B.; Chen, S.; Opeil, C.; Broido, D.; Chen, G.; Ren, Z. Heavy Doping and Band Engineering by Potassium to Improve the Thermoelectric Figure of Merit in $\mathrm{P}$ Type PbTe, PbSe, and $\mathrm{PbTe}_{1-\gamma} \mathrm{Se}_{\mathrm{y}}$. L.Am. Chem. Soc. 2012, 134, 10031-10038.

(88) Ohta, M.; Biswas, K.; Lo, S.-H.; He, J.; Chung, D. Y.; Dravid, V. P.; Kanatzidis, M. G. Enhancement of Thermoelectric Figure of Merit by the Insertion of MgTe Nanostructures in P-Type PbTe Doped with $\mathrm{Na}_{2} \mathrm{Te}$. Adv. Enerav Mater. 2012, 2, 1117-1123.

(89) Jood, P.; Ohta, M.; Kunii, M.; Hu, X.; Nishiate, H.; Yamamoto, A.; Kanatzidis, M. G. Enhanced

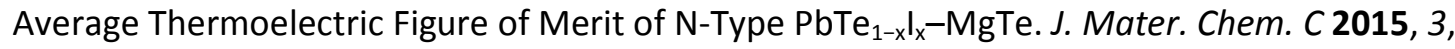
10401-10408.

(90) Qian Zhang, Y. L. Increased Thermoelectric Performance by $\mathrm{Cl}$ Doping in Nanostructured $\mathrm{AgPb}_{18} \mathrm{SbSe}_{20-\mathrm{x}} \mathrm{Cl}_{\mathrm{x}}$. Nano Enerav 2013, 2, 1121-1127.

(91) Wang, H.; Bahk, J.-H.; Kang, C.; Hwang, J.; Kim, K.; Kim, J.; Burke, P.; Bowers, J. E.; Gossard, A. C.; Shakouri, A.; et al. Right Sizes of Nano- and Microstructures for High-Performance and Rigid Bulk Thermoelectrics. Proc. Natl.Acad. Sci. U.S.A. 2014, 111, 10949-10954.

(92) Banik, A.; Biswas, K. Agl Alloying in SnTe Boosts the Thermoelectric Performance via Simultaneous Valence Band Convergence and Carrier Concentration Optimization. J. Solid State Chem. 2016, 242, 43-49.

(93) Banik, A.; Vishal, B.; Perumal, S.; Datta, R.; Biswas, K. The Origin of Low Thermal Conductivity in $\mathrm{Sn}_{1-\mathrm{x}} \mathrm{Sb}_{\mathrm{x}} \mathrm{Te}$ : Phonon Scattering via Layered Intergrowth Nanostructures. Enerav Environ. Sci. 2016, 9, 2011-2019.

(94) Al Rahal Al Orabi, R.; Mecholsky, N. A.; Hwang, J.; Kim, W.; Rhyee, J.-S.; Wee, D.; Fornari, M. Band Degeneracy, Low Thermal Conductivity, and High Thermoelectric Figure of Merit in SnTe-CaTe Alloys. Chem. Mater. 2016, 28, 376-384. 
TOC Graphics

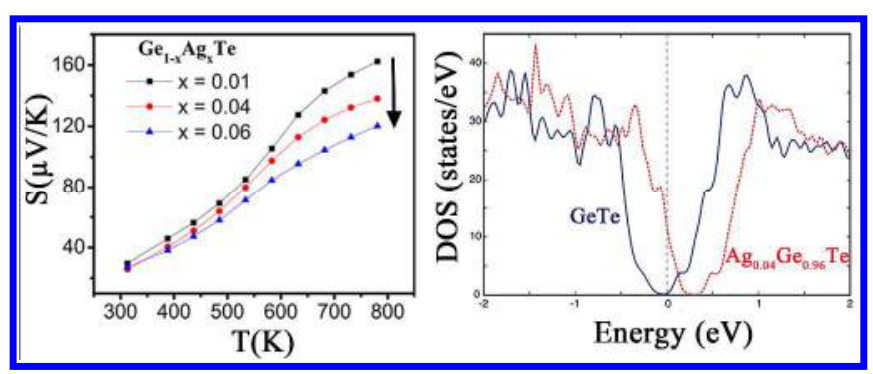



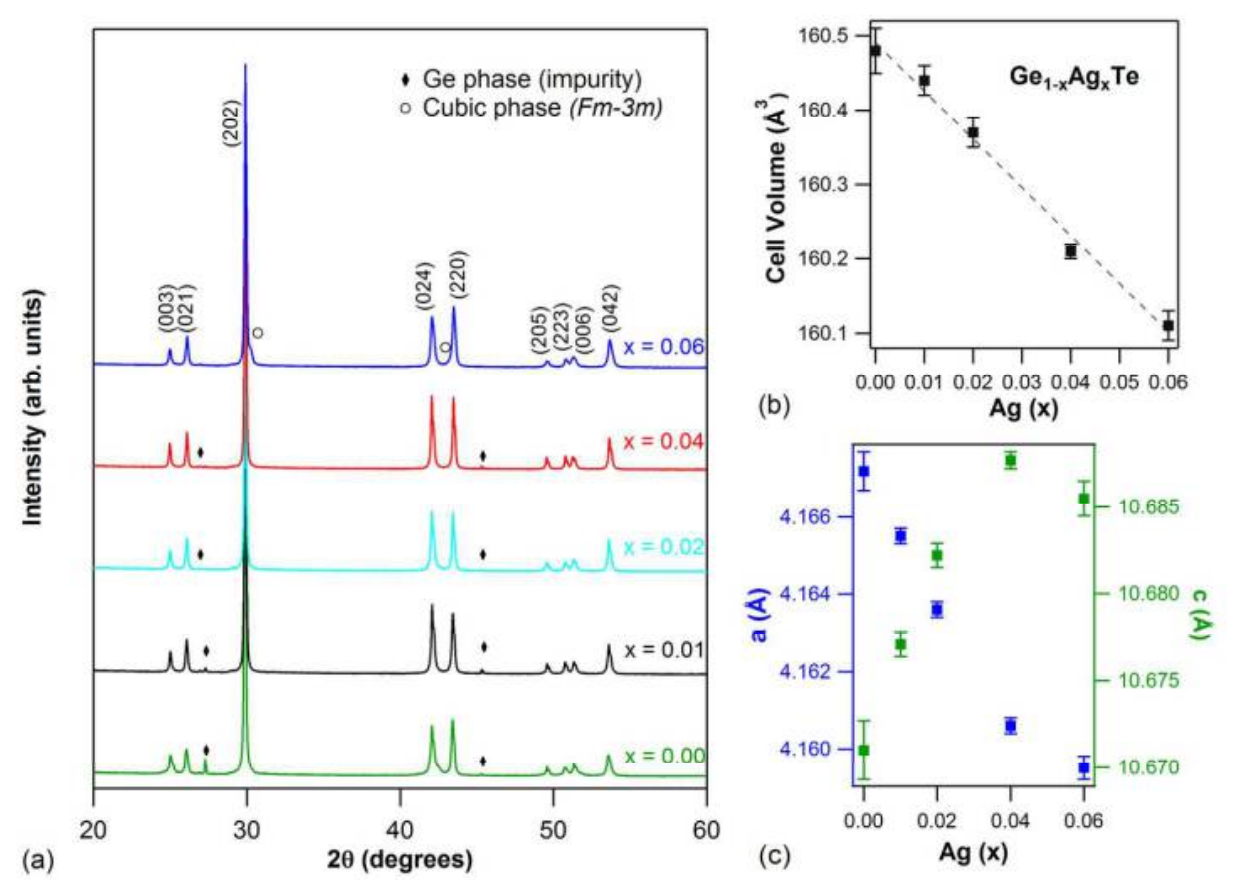

Figure 1

$153 \times 106 \mathrm{~mm}(300 \times 300$ DPI $)$ 
Page 27 of 326 


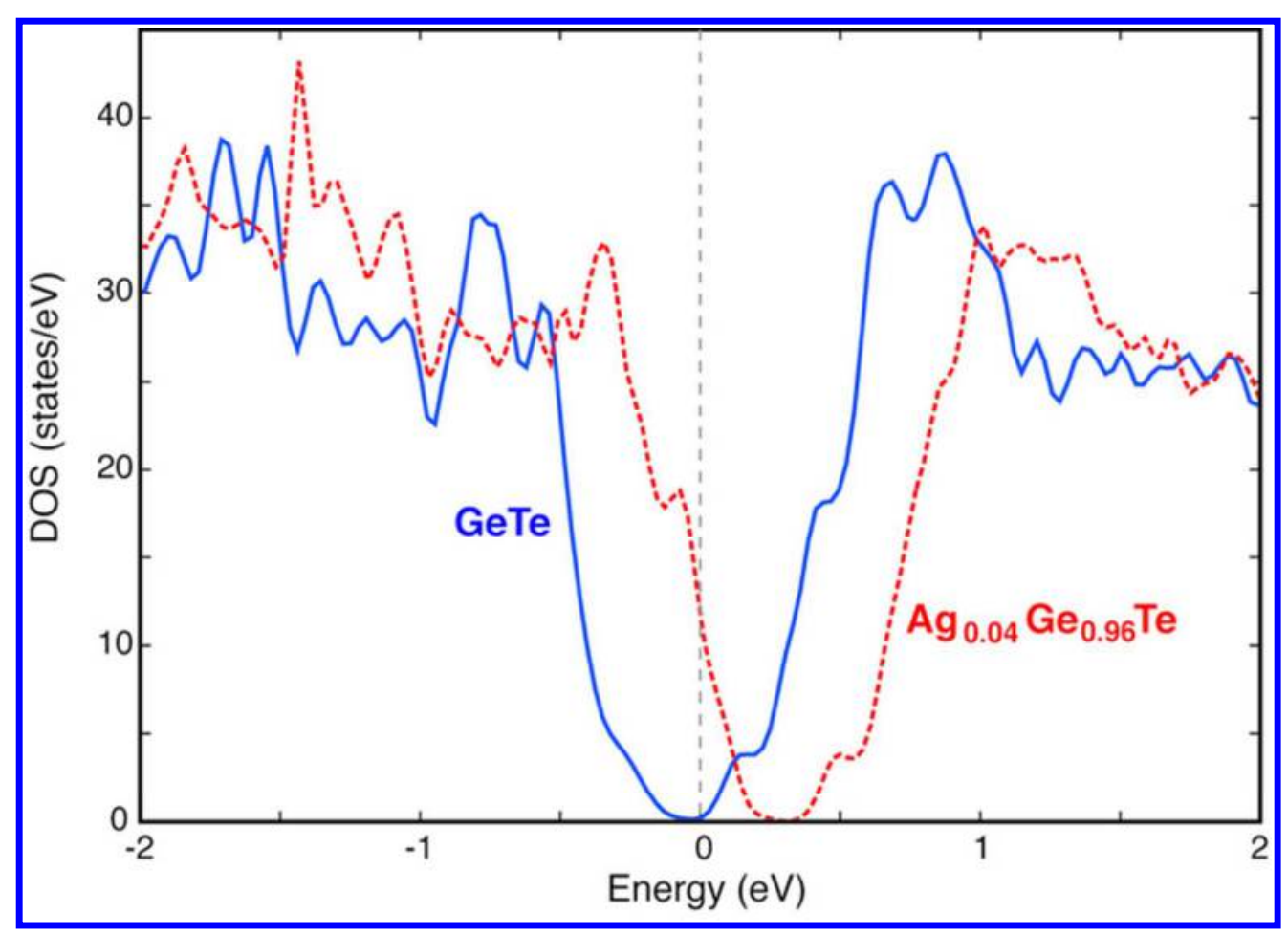

Figure 3

$59 \times 42 \mathrm{~mm}(300 \times 300 \mathrm{DPI})$ 


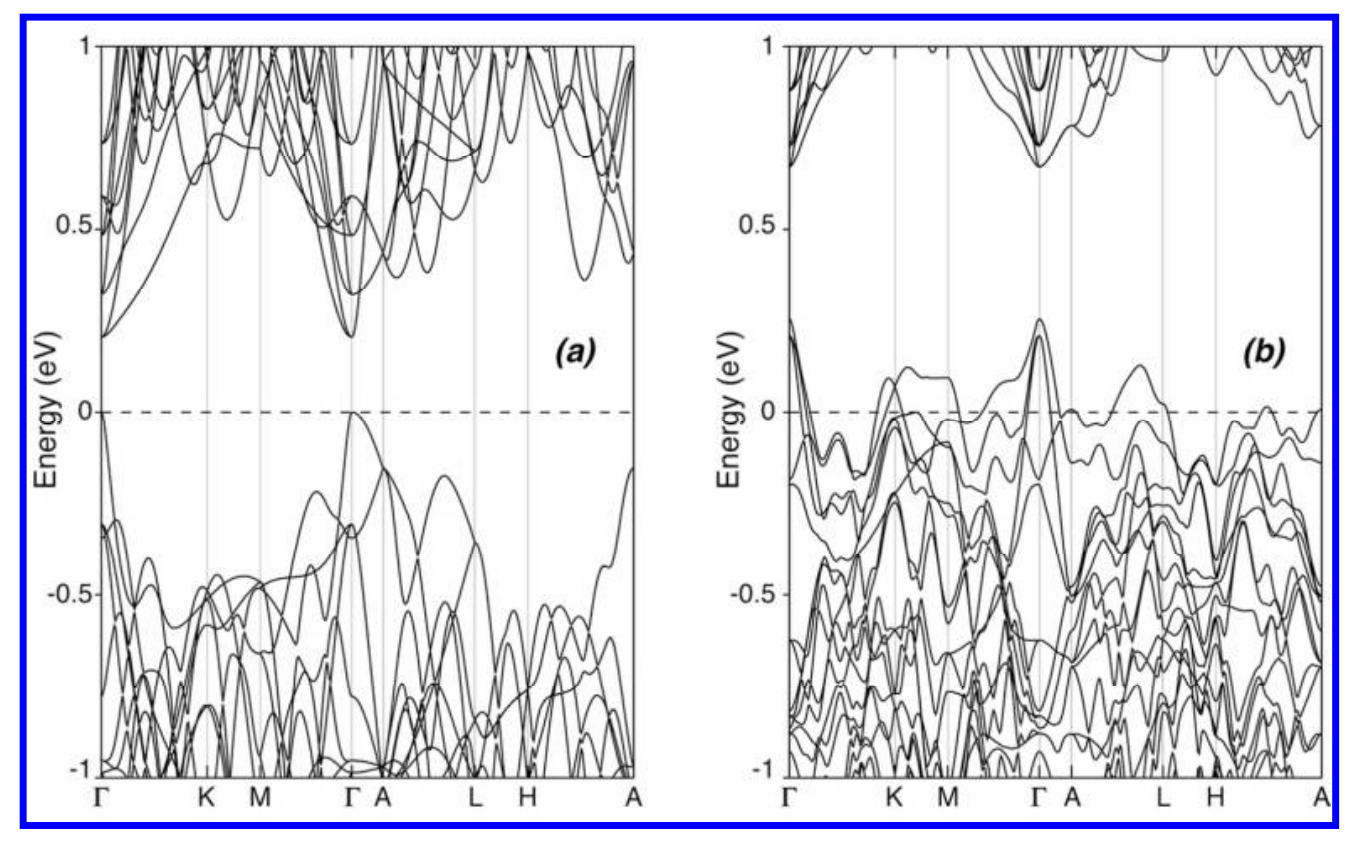

Figure 4

$103 \times 63 \mathrm{~mm}(300 \times 300$ DPI $)$ 


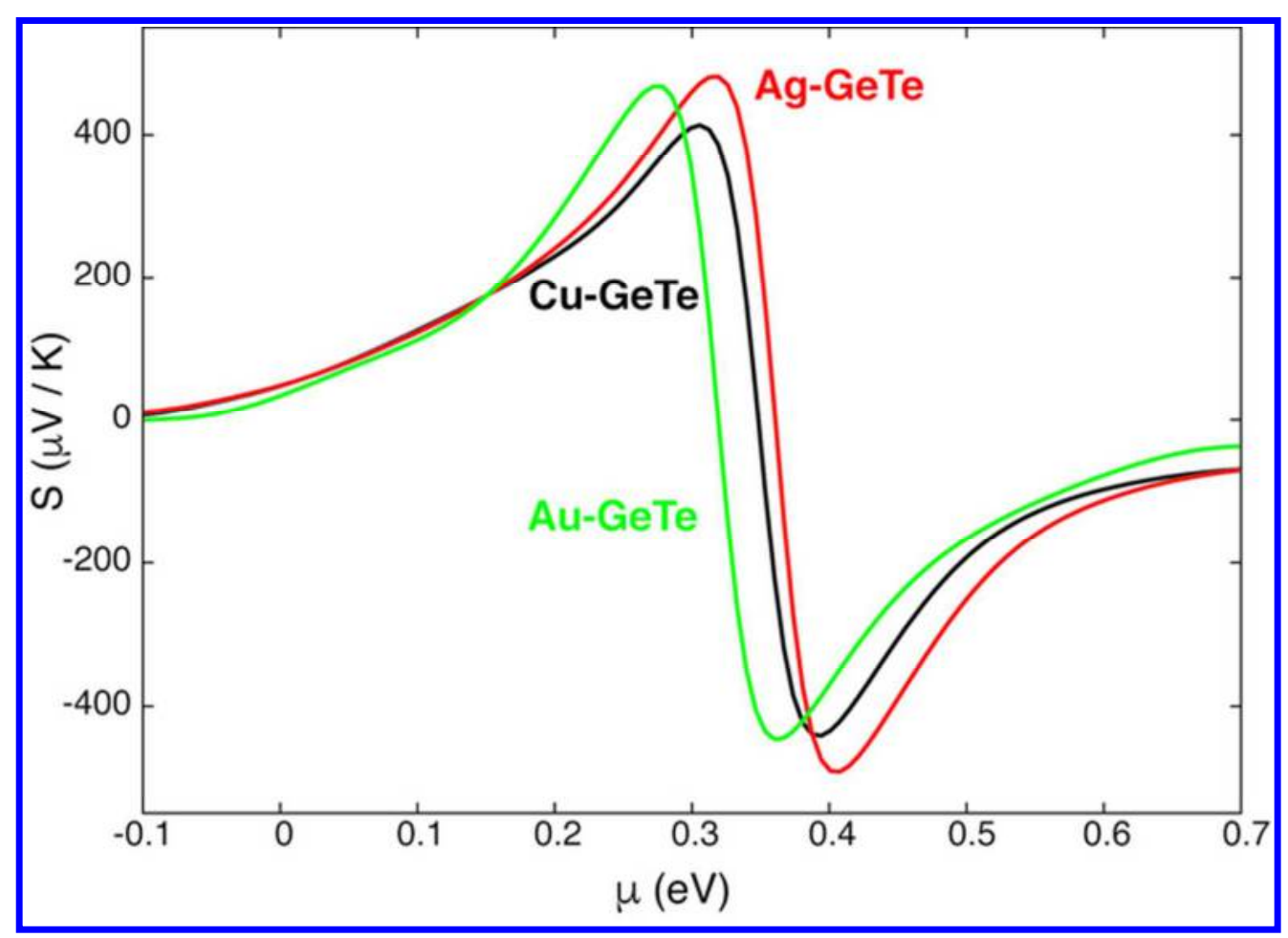

Figure 5

$59 \times 42 \mathrm{~mm}(300 \times 300 \mathrm{DPI})$ 


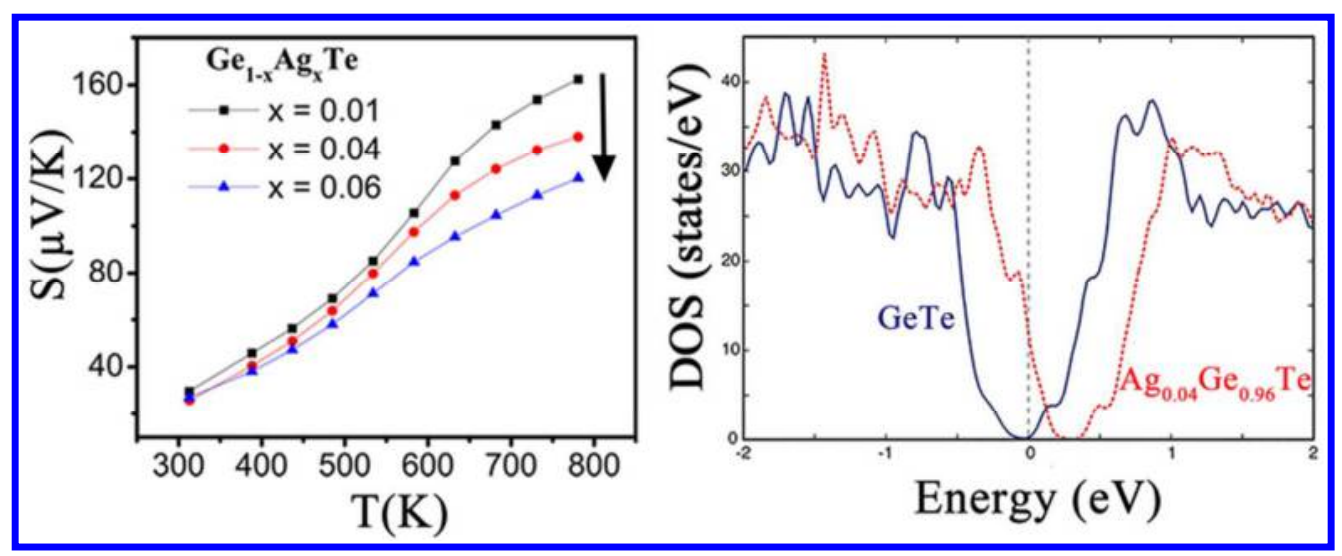

TOC Graphic

$33 \times 13 \mathrm{~mm}(600 \times 600 \mathrm{DPI})$ 